\title{
Environments And Hosts Structure The Bacterial Microbiomes Of Fungus-Gardening Ants And Their Symbiotic Fungus Gardens.
}

\section{Blake Bringhurst}

University of Texas at Tyler

Mattea Allert

University of Texas at Tyler

Matthew Greenwold

University of Texas at Tyler

Katrin Kellner

University of Texas at Tyler

Jon Nicholas Seal ( $\square$ trachymyrmex@gmail.com )

University of Texas at Tyler https://orcid.org/0000-0001-8013-1438

\section{Research Article}

Keywords: Trachymyrmex, Mycetomoellerius, microbiome, fungus-gardening ants

Posted Date: March 7th, 2022

DOI: https://doi.org/10.21203/rs.3.rs-1409160/v1

License: (9) This work is licensed under a Creative Commons Attribution 4.0 International License.

Read Full License 


\section{Abstract}

The fungus gardening-ant system is considered a complex, multi-tiered symbiosis, as it is composed of ants, their fungus, and microorganisms associated with either ants or fungus. We examine the bacterial microbiome of Trachymyrmex septentrionalis and Mycetomoellerius turrifex ants and their symbiotic fungus gardens, using 16S rRNA Illumina sequencing, over a large geographical region (east and central Texas). Typically microorganisms can be acquired from a parent colony (vertical transmission) or from the environment (horizontal transmission). Because the symbiosis is characterized by co-dispersal of the ants and fungus, elements of both ant and fungus garden microbiome could be characterized by vertical transmission. The goals of this study were to explore how both the ant and fungus garden bacterial microbiome are acquired. The main findings were that different mechanisms appear to explain the structure the microbiomes of ants and their symbiotic fungus gardens. Ant associated microbiomes had a strong host ant signature, which suggests vertical inheritance of the ant associated bacterial microbiome. On the other hand, the bacterial microbiome of the fungus garden was more complex in that some bacterial taxa appear to be structured by the ant host species, whereas others by fungal lineage or the environment (geographic region). Thus bacteria in fungus gardens appear to be acquired both horizontally and vertically.

\section{Introduction}

Symbioses with microorganisms have been crucial to the success of insects, if not eukaryotic life in general (Klepzig et al., 2009; McFall-Ngai et al., 2013; Douglas, 2014, 2015; Parfrey et al., 2018). One of the most striking discoveries is that many symbioses often consist of more than a single host and a single symbiont, and are best viewed as a community of macro- and microorganisms (Moran, 2001; Woyke et al., 2006; Douglas, 2010; Johansson et al., 2013; Klassen, 2019; Brown et al., 2020). One of the central issues facing symbiology (the study of symbioses) is understanding how these complex entities are organized and function in a dynamic world, especially with regard to the mechanisms that maintain specificity and homeostasis between hosts and microbial symbionts (Douglas, 2010; Silverstein et al., 2012; Garcia \& Gerardo, 2014; Hambleton et al., 2014; Dheilly et al., 2015; Parfrey et al., 2018). For example, insects often have a microbiome that is structured toward particular life history, e.g., with microorganisms often supplying key nutrients or resources that essentially 'upgrade' specialized but otherwise poor diets (Douglas, 2011; Feldhaar, 2011; Douglas, 2015) or employing symbionts as defense against pathogens (Kaltenpoth \& Engl, 2013; Clay, 2014; Van Arnam et al., 2018). Ants are among the most ecologically important insects, which can be attributed to their large colonies, population sizes and diversity in diets (King et al., 2013; Parr et al., 2016; Farji-Brener \& Werenkraut, 2017; Swanson et al., 2019). While ants have a digestive system similar to most omnivorous insects, they may feed on a variety of food sources and employ symbionts to upgrade their diets (Blüthgen et al., 2003; Davidson et al., 2003). For example, some ants may harbor bacteria that fix nitrogen or involved in N cycling generally (Borm et al., 2002; Neuvonen et al., 2016; Hu et al., 2018). 
The fungus gardening ant (tribe Attini) symbiosis has long been known as a complex system of interacting macro- and microsymbionts. For example, Actinobacteria cultivated via exocrine glands on some attine species' cuticle produce secondary metabolites that appear to have a defensive function against predatory fungal species (Escovopsis spp.) (Meirelles et al., 2014; Li et al., 2018; Montoya et al., 2021). The relationship between Actinobacteria and Escovopsis spp. appears to have a long coevolutionary history with the fungus-gardening ant symbiosis (Cafaro et al., 2011; Osti \& Rodrigues, 2018), though some Actinobacteria may be environmentally acquired (Mueller et al., 2010). Likewise, Burkholderia bacteria associated with fungus gardens also appear to have antimicrobial function (Francoeur et al., 2021). Certain yeasts may be antagonists towards Actinobacteria and nitrogen fixing bacteria may provide amino acids to the ants (Little \& Currie, 2008; Pinto-Tomás et al., 2009; Rodrigues et al., 2009). Microfungi may also serve important nutritional, detoxification and defensive functions against specialist and general competitors and predators of the fungus garden (Rodrigues et al., 2009). Much of our understanding has focused on the species found in the tropics, which may or may not be representative of the interactions occurring in all fungus-gardening symbioses. For instance, the specialized predatory fungus (Escovopsis) is not thought to be very common in temperate attines (Rodrigues et al., 2011) and other bacterial taxa may be just as important if not more important than Actinobacteria (Ishak et al., 2011). As a result, detailed intraspecific natural history studies of microbiomes of ants and their symbiotic fungi may increase our understanding of the roles of microbial associates (Kaltenpoth \& Engl, 2013).

With the advent of next-generation methods, the structure of the microbial communities of fungusgardening ants is only beginning to be understood. The bacterial communities of fungus-gardens typically are characterized by few genera that make up the vast majority of the microbiome; for example, Atta colombica and Atta cephalotes fungus gardens contained primarily Enterobacter, Klebsiella, Citrobacter, Escherirchia, and Pantoea, i.e., bacteria that are often found in herbivore digestive systems (Aylward et al., 2012). Probably because attine ants have outsourced most digestion to the external fungal symbiont, the gut microbiome appears to be less diverse and may have a relatively minor role with regard to digestion (Sapountzis et al., 2015; Sapountzis et al., 2019). The function of many bacterial taxa residing in fungus gardens are poorly understood; for instance, notably, researchers found that fungal inocula contained a high amount of Mesoplasma, the colony was more likely to decline, though it was unclear whether this was correlative or causal (Meirelles et al., 2016). Ishak et al. (2011) examined the microbes present in the fungus gardening ants Trachymyrmex septentrionalis; the results indicate that Actinobacteria (e.g., Pseudonocardia sp., Kribbela sp., Amycolatopsis sp., and Streptomyces $s p$ ) and Mollicutes were the most abundant bacterial taxa in the fungus of $T$. septentrionalis. Ishak et al (2011) suggested that ants within the same colony and colonies have distinct microbiomes. A recent comparative study illustrated that five different attine species and their colonies harbor distinct microbial communities from one another (Ronque et al., 2020).

Like many symbioses, attine symbionts are obtained from a mix of horizontal and vertical transmission. For example, the fungus garden is typically vertically transmitted from parent colony to gynes (new queens) (Mikheyev et al., 2007; Schultz \& Brady, 2008; Mueller et al., 2018; Beigel et al., 2021). 
Actinobacteria, are also thought to be primarily vertically transmitted, since clades of ants typically grow similar strains of Pseudonocardia (Mikheyev et al., 2008; Cafaro et al., 2011). On the other hand, some studies have documented sharing of fungal symbionts among ant species and environmental acquisition of bacteria (Kellner et al., 2015; Schultz et al., 2015; Mueller et al., 2018; Beigel et al., 2021). Unfortunately, there have been very few studies that have taken a comparative approach to determine how the microbiomes of these symbioses are acquired.

Although research is accumulating on fungus gardening-ant microbiomes, not many studies have examined how geography, host species or type of fungal symbiont may influence the structure of microbial communities (Kellner et al., 2015; Meirelles et al., 2016; Ronque et al., 2020). For example, ants in the 'higher attine genera' (Mycetomoellerius, Paratrachymyrmex, Seriocomyrmex and Trachymyrmex), grow conservatively five lineages of fungi and may host switch to varying degrees (Mikheyev et al., 2008; De Fine Licht \& Boomsma, 2014; Ješovnik et al., 2017; Solomon et al., 2019; Luiso et al., 2020; Beigel et al., 2021). It remains unknown how the microbiome may be altered as members of the symbiosis are added or lost, such as by fungal symbiont switching observed among many host ant species (Mikheyev et al., 2007; Mikheyev et al., 2008; De Fine Licht \& Boomsma, 2014; Schultz et al., 2015; Mueller et al., 2018; Luiso et al., 2020; Beigel et al., 2021). Unfortunately, there have been very few microbiome studies that examine both ants and fungus gardens across ecological scales (Ishak et al., 2011; Kellner et al., 2015). Studies have focused on fungus garden bacterial microbiome structure (Aylward et al., 2012; Meirelles et al., 2016) or solely on ants (Sapountzis et al., 2015; Sapountzis et al., 2019; Ronque et al., 2020). Similarly, Ishak et al (2011) examined temporal patterns of microbiome structure, whereas Kellner et al (2015) examined spatial components. Groundbreaking - yet limited - studies like the latter are needed because the ants, fungus and many of their bacterial associates are clearly interacting with one another across ecological and evolutionary scales (Schultz \& Brady, 2008; Seal \& Mueller, 2014; Seal et al., 2014; Mueller et al., 2018; Beigel et al., 2021). Therefore conclusions drawn from the microbiome of only one partner of the symbiosis are limited.

To unravel what factors influence the microbiome of $T$. septentrionalis and $M$. turrifex ants and their symbiotic fungus, we examined the bacterial microbiome of the ants and symbiotic fungi of $T$. septentrionalis and $M$. turrifex across a portion of their shared ranges. The broad goal of this study was to characterize the bacterial microbiome of $T$. septentrionalis and $M$. turrifex and their symbiotic fungus garden and determine potential drivers of this variation. Specifically, we had four main questions: 1) Do the ant species harbor different bacterial communities? 2) Do the two ant species influence the bacterial community structure of the fungus gardens? 3) Are fungal lineages characterized by different microbiomes? 4) Are there geographical differences in the structure of ant or fungal bacterial microbiomes?

\section{Materials And Methods}

\section{Study area}


Samples of both ants and fungus garden materials were obtained during May and June, 2016 from field colonies from sites in two broad regions in east-central Texas. Samples were obtained from four sites in northeast Texas in close proximity to Tyler, Texas ('East Texas') (approximately $32.29^{\circ} \mathrm{N} 95.24^{\circ} \mathrm{W}$ ) and from three sites approximately $300 \mathrm{~km}$ away in Bastrop, Texas (approximately $29.39^{\circ} \mathrm{N} 97.32^{\circ} \mathrm{W}$ ) ('Central Texas') (Fig. 1). Both species of ants co-occur at most of the same locations (Fig. 1, Table 1). Although all of these sites occur in the Post Oak Savanna Ecoregion, which is characterized by sandy soils and an overstorey of post oaks (Quercus stellata) and occasionally loblolly or shortleaf pine (Pinus taeda and P.echinata, respectively) and understory shrubs such as yaupon holly (Ilex vomitoria) and eastern redcedar (Juniperus virginiana), East Texas tends to be wetter than Central Texas $(115 \mathrm{~cm}$ vs. $90 \mathrm{~cm}$ of precipitation per year, respectively) (Diggs et al., 2006). The latter is especially known for extreme droughts where less than $30 \mathrm{~cm}$ of rain may fall in a year (Moore et al., 2016). Central Texas is also the western limit of $T$. septentrionalis whereas East Texas (and western Louisiana) is the eastern limit of $M$. turrifex (Rabeling et al., 2007; Seal et al., 2015; Senula et al., 2019; Luiso et al., 2020).

\section{Sampling Methods}

We collected up to five adult ants from each colony of both species; these ants were pooled into a single DNA extract to account for heterogeneity among individual ants in the colony (Ishak et al., 2011). Ants were collected directly from inside fungus gardens with ethanol and flame-sterilized forceps, meaning that the ants collected were likely garden workers (i.e., not foragers who could pick up bacteria inadvertently while outside the nest). Roughly an equal number of $T$. septentrionalis and $M$. turrifex colonies from our samples of the East Texas and Central Texas populations were utilized ( $N=13$ for $T$. septentrionalis and $\mathrm{N}=11$ for $M$. turrifex) (Table 1). A small sample of fungus garden material was collected similarly with flame and ethanol sterilized forceps from the same garden chambers where the ants were collected. Lastly, seven soil samples were taken from within the nest fungal chambers $(\mathrm{N}=4$ from East Texas and $\mathrm{N}=3$ from Central Texas) to act as a negative control, and make sure the microbe communities observed with the ant or fungal samples were not a relic of soil contamination. All samples were preserved immediately upon collection in $100 \%$ ethanol.

\section{Fungal Genotyping}

Each fungus garden was genetically identified to phylotype (clade) using the terminology and methods of Luiso et al. (2020). Briefly, gongylidia (swollen hyphal tips diagnostic feeding structures of higher fungus-gardening ants) were plucked off the fungus with flame-sterilized forceps, placed in an aqueous solution of Chelex, and heated in a thermal cycler (Luiso et al., 2020). Before PCR amplification, the DNA extract was diluted (1:10) using nuclease free water (higher concentrations of DNA inhibited PCR reactions). The PCR was performed using the ITS 4 and ITS 5 primers to amplify the 18S rRNA ITS gene (White et al., 1990; Luiso et al., 2020). The resulting PCR products were sent to the DNA Sequencing Facility at the University of Texas at Austin for Sanger sequencing on an Applied Biosystems 3730 DNA Analyzer. The resulting ITS sequences were cleaned up and aligned in Geneious 10.1.2 (Kearse et al., 
2012). Sequencing errors or misreads in the DNA sequences were manually corrected. Sequences were identified using BLAST and personal databases of ITS sequences (Table 1) (Luiso et al., 2020).

\section{DNA Extraction, PCRs and Sequencing of Microbiomes}

DNA extraction and sequencing of the $16 \mathrm{~S}$ samples was performed at MRDNA in Shallowater, Texas (http://www.mrdnalab.com/). DNA sequences were amplified from whole ants and fungus using primers Gray28F 5'GAGTTTGATCNTGGCTCAG and Gray519R 5'GTNTTACNGGGCKGCTG that span the V1-V3 hypervariable regions of the 16S rRNA gene. They were processed using the HotStarTaq Plus Master Mix Kit (Qiagen, USA) under the following conditions: $94^{\circ} \mathrm{C}$ for 3 minutes, followed by 28 cycles of $94^{\circ} \mathrm{C}$ for 30 seconds, $53^{\circ} \mathrm{C}$ for 40 seconds and $72^{\circ} \mathrm{C}$ for 1 minute, after which a final elongation step at $72^{\circ} \mathrm{C}$ for 5 minutes was performed. After the samples were amplified and checked for adequate genetic yields, the sub-samples were pooled back together and purified using calibrated Ampure XP beads. The purified and pooled PCR product was used to create a DNA library and sequenced using the Illumina MiSeq platform in PEx300 mode. Sequences have been deposited in the NCBI Sequence Read Archive under the BioProject PRJNA789907.

\section{Microbiome Bioinformatics}

Initial sequence cleanup was performed by removing short sequences with $<150 \mathrm{bp}$, sequences with ambiguous base calls, chimeras, sequences with runs exceeding $6 \mathrm{bp}$, and singleton sequences (Dowd et al., 2008). The resulting sequences were then inputted into Qiime2-2020.6, after having their barcodes and linker and reverse primers removed (Bolyen et al., 2019). Sequences were then demultiplexed using the demux plugin https://github.com/qiime2/q2-demux and went through quality control using the dada2 plugin (Callahan et al., 2016). When using the dada2 plugin, sequences were truncated down to 260 base pairs as the average quality score dipped below 20 beyond this point. Taxonomy classification with $99 \%$ OTU similarity was performed utilizing the SILVA 132_QIIME database (Quast et al., 2013; Yilmaz et al., 2014). To do this, we created our own taxonomic classifier using the "feature-classifier fit-classifier-naivebayes" command and the SILVA database. This classifier was used to assign sequences a taxonomic classification using the "feature-classifier" plugin (Bokulich et al., 2018) with the "classify-sklearn" command. An OTU table was created by inputting a tabulated taxonomic bar plot, created using the "taxa barplot" command, of our sequences into Qiime2 View (https://view.qiime2.org). OTUs that matched with chloroplast or mitochondrial sequences were manually removed from the OTU table prior to any further analyses.

This OTU table can be found on Dryad Digital Repository https://doi.org/10.5061/dryad.7wm37pvv1. The Qiime2 processing pipeline has been deposited on GitHub (https://github.com/bsbringhurst/TS-and-MTMicrobiome-Files).

\section{Statistical Methods}


The VEGAN R package was used to calculate the Shannon's Diversity Index $(\mathrm{H})$ for every ant, fungal garden, and soil sample (Oksanen et al., 2018). The respective average Shannon's Diversity Index values were then compared among groups (ant host, fungal clade or region), using either Welch's two sample ttests or ANOVAs, for the ant and fungal garden samples. A Tukey's Honest Significant Difference test was performed using the multcomp package in $\mathrm{R}$ as the post-hoc analysis to compare Shannon's Diversity Index values among groupings with three different groups (Hothorn et al., 2008). EstimateS v9.1.0 was used to create rarefaction curves to compare OTU richness among groups of ant and fungal garden samples as well as compare sampling adequacy (Colwell, 2013). Rarefaction curves were plotted along with their respective $95 \%$ confidence interval. These rarefaction curves were additionally extrapolated out to 20 samples if a variable category did not contain over 20 samples to further illuminate differences between the variable categories due to their small sample sizes. Finally, indicspecies R package was used to conduct an indicator species analysis (ISA) (with each analysis having 9,999 permutations) to examine which bacterial taxa contribute most toward the overall variation in microbiome structure of the ant and fungal garden samples (Cáceres \& Legendre, 2009).

\section{Multivariate Statistics}

Since our ant and fungal samples were confounded by multiple variables (host ant species $(\mathrm{N}=2)$, fungal garden clade $(\mathrm{N}=3)$ and geographic region $(\mathrm{N}=2)$ ), we explored how much variation in microbiome structure was explained by these variables. To see any initial patterns in the data, we first constructed non-metric multidimensional scaling (NMDS) plots based off of Bray Curtis distances using the VEGAN R package to visualize patterns between the ant and fungal microbiomes (Oksanen et al., 2018. To look for statistical significance in these patterns, we then created OTU tables with a subset of either the ant or fungal samples. A detrended correspondence analysis (DCA) was performed on each of the two OTU tables (ants or fungus) utilizing the VEGAN R package that then determined whether a canonical correspondence analysis (CCA) or redundancy analysis (RDA) was best tool (Oksanen et al., 2018). A threshold value of 4 for the DCA Axis 1 was used during the DCA to denote whether a CCA or RDA was to be used, with a value greater than 4 denoting that a CCA was optimal (Oksanen et al., 2018). Each CCA or RDA was performed under a reduced model and used 10,000 permutations.

To further quantify differences between the microbial communities of the ants and their fungus gardens, CCAs or RDAs were performed on major bacterial classes identified by the significant OTUs in the ISAs to determine whether host ant, fungal lineage or region played any role in community structure of these groupings. These tests were performed on OTU tables consisting of the subset of OTUs corresponding to significant taxonomic groups revealed by the ISA. Further ISAs were performed on all the OTUs within these bacterial classes to highlight which taxa might be driving the overall patterns.

\section{Results}

\section{Bacterial Distribution}


After the raw data was processed and filtered through Qiime2, the dataset consisted of 1,003,775 sequences, with 481,514 sequences associated with the 24 ant samples, 470,669 sequences associated with the 24 fungal samples, and 51,592 sequences associated with the 7 soil samples. From these resulting sequences, 1,065 OTUs were detected, with 334 of these OTUs found within the ant samples, 775 OTUs found within the fungal samples, and 513 OTUs found the soil samples.

\section{Regional Analysis of Ant, Fungus, and Soil Microbiome:}

Initial multivariate analysis of the ant and fungal samples indicated that ants, fungus and soil samples formed visually distinct clusters (Fig. S1; stress $=0.184$ ). Moreover, ants, fungus, and soil bacterial microbiomes were significantly different from one another $(C C A ; F=3.1581, d f=2, p<0.0001)$. The ant $(H=1.946)$, fungus garden $(H=1.947)$, and soil samples $(H=4.019)$ had significantly different

Shannon's Diversity Index values $\left(F=12.68, d f=2, p=3.27 \times 10^{-5}\right)$, with the soil samples having a significantly higher average in comparison to the ant and fungus garden samples (Fig. S2). These results confirm that microbial communities of ants and fungus we were analyzing in this study are not contaminants originating from the surrounding soils. In all subsequent analyses, soils were removed since they were of no primary interest.

\section{Ant Microbiome Composition}

The two ant species were the primary driver of their microbiome $(C C A ; F=3.8141, d f=1, p<0.0001)$, whereas fungus garden clade $(F=0.8464, d f=2, p=0.6684)$ and region $(F=0.6298, d f=1, p=0.8807)$ did not appear to have significant roles in structuring the bacterial microbiome of ants. These findings were corroborated with NMDS plots showing that the ant samples formed distinct clusters based on species (Fig. 2a; stress $=0.190$ ), and not region (Fig. 2b; stress $=0.190$ ). Additionally, NMDS plots showed that $T$. septentrionalis had a less variable microbiome than $M$. turrifex, since $T$. septentrionalis ant samples were more clustered together while M. turrifex ant samples were more variable (Fig. 2a).

Ant microbiomes appeared to be structured by different bacterial taxa. The three most common bacterial taxa in the microbiome of $T$. septentrionalis ants were one strain of Solirubrobacter $(29.409 \%)$, Luteimonas (15.8\%), and an unknown member of Burkholderiaceae (9.209\%) (Table 2a). In contrast, the three most common taxa in the microbiome of M. turrifex ants were Amycolatopsis (19.814\%), an unknown member of Burkholderiaceae (14.633\%), and an undescribed member of Microbacteriaceae (10.530\%) (Table 2b). Additionally, Pseudonocardia strains consisted of $5.760 \%$ of the M. turrifex ant microbiome whereas it was nearly absent in $(<1 \%) T$. septentrionalis ants, (Table $2 \mathrm{a}, \mathrm{b})$. The indicator species analysis (ISA) of these two ant species also suggested different core microbiomes; with the Actinobacteria, Amycolatopsis (indicator value (IV) $=0.539, \mathrm{p}=0.0001$ ) and Pseudonocardia $(\mathrm{IV}=0.500$, $p=0.001$ ) strains were the top two significant contributors to overall variation in the $M$. turrifex ant microbiome whereas two strains of Solirubrobacter (IV $=0.894, p=0.0001 ; \mathrm{IV}=0.816, p=0.0001$ ) were the top significant contributors to overall variation within the $T$. septentrionalis microbiome (Table $3 a, b$, Table S1). As a next step, we probed whether bacterial diversity in the classes identified as significant in 
the ISA were explained by 1) geographic region, 2) ant species or 3) fungal garden clade (Table S1). The ISA reported that four bacterial classes (Actinobacteria, Alphaproteobacteria, Bacteroidia, and Gammaproteobacteria) were important in describing the variation among ants. The Actinobacteria community of the ants was primarily explained by the ant species (CCA; Table 4a). Similarly, the Alphaproteobacteria and the Gammaproteobacteria communities of the ants were explained by ant species (CCA; Table 4a). However, the Bacteroidia community for the ants was not explained by any variable (RDA; Table 4a). The ISA found 15 significant OTUs within the Actinobacteria community that differed between the two ant species. OTUs of Pseudonocardia and Amycolatopsis associated with M. turrifex and OTUs of Naumannella, an undescribed Intrasporangiaceae, and Aeromicrobium within T. septentrionalis were important drivers in overall discrimination between the two ant associated Actinobacteria communities (Fig. 3a,b). Other significant OTUs driving the differentiation in the Alphaproteobacteria between the two ant species included a Sphingomonas OTU in M. turrifex and within the Gammaproteobacteria, a Lutimonas OTU in T. septentrionalis (Fig. S3a,b).

Despite community level differences in taxa comprising the bacterial microbiomes of the two ant species, overall diversity of the two species was similar. Although $M$. turrifex was projected to have significantly more OTUs than T. septentrionalis (Fig. 2c), there was not a statistical difference in the average Shannon's Diversity Index of bacteria between $T$. septentrionalis $(H=1.902)$ and $M$. turrifex $(H=1.998)$ ants $(t=0.70803, d f=22, p=0.4864)$.

\section{Fungal Microbiome Composition}

Unlike ant bacterial microbiomes, geographic region appeared a greater role in structuring the bacterial microbiome of the fungus garden, though this was not statistically significant (CCA; $F=1.3466, d f=1, p$ $=0.1065)$ than fungal clade $(F=0.9482, d f=2, p=0.5223)$ or host ant species $(F=1.0390, d f=1, p=$ 0.3347). The three most common taxa in the microbiome of East Texas fungus were Mesoplasma (57.891\%) and two strains of Spiroplasma $(21.857 \%, 5.020 \%)$ (Table 5a). The three most common taxa in the microbiome of Central Texas fungus were Mesoplasma (31.797\%), Pseudomonas (8.750\%), and Tyzzerella (4.880\%) (Table 5b).

The ISA found that two OTUs defined East Texas fungus while 47 OTUs defined the Central Texas fungi; with most of these indicator OTUs found in the families Acetobacteraceae, Acidobacteriaceae, Burkholderiaceae, Cthoniobacteraceae, Enterobacteriaceae, Sphingobacteriaceae, and Weeksellaceae (Table 3c,d, Table S2). Except for a single undescribed OTU in the genus Entomoplasma, no members of the Entomoplasmataceae (the family of the most common taxa, Mesoplasma) were significant members of the fungus garden bacterial microbiomes (Tables 3,S2).

Since Mesoplasma was very common in the fungus garden samples, yet seemed to poorly characterize fungus garden microbiome structure (per the ISA), sequences of Mesoplasma were removed to examine for patterns among the other bacterial taxa. Without Mesoplasma, the fungus microbiome was significantly determined by region (CCA; $F=1.5921$, $d f=1, p=0.0106)$, whereas fungal clade $(F=0.8532$, $\mathrm{df}=2, \mathrm{p}=0.7251)$ and host ant species $(F=1.0982, \mathrm{df}=1, \mathrm{p}=0.2832)$ were not significant factors in 
structuring fungus garden microbiomes. These findings were corroborated with an NMDS plot showing that the fungal samples formed clusters based around their region (Fig. 4, stress $=0.145$ ).

The ISA reported that five bacterial classes (Acidobacteriia, Actinobacteria, Alphaproteobacteria, Bacteroidia, and Gammaproteobacteria) were important in describing the variation among the fungus gardens (Table 3 and S2). As with the ants, the following analyses probed whether variation in the OTUs in these classes were explained by 1) geographic region, 2) host ant species or 3 ) fungal clade. The Acidobacteria community of the fungus gardens was explained by both fungal clade and the region (RDA; Table 4b). The Actinobacteria community of fungus gardens was significantly explained by the host ant species, but the fungal clade may play a role in determining community variation, though the test was not statistically significant (CCA; Table 4b), but low enough to warrant concern about a Type II error. The Alphaproteobacteria community of fungus gardens was explained by host ant species and by fungal clade (CCA; Table $4 \mathrm{~b})$. The Gammaproteobacterial community of fungus gardens was explained by ant species (CCA; Table 4b). The Bacteroidia community for fungus gardens was not explained by any variable (RDA; Table $4 \mathrm{~b}$ ). The ISAs within the Acidobacteriia community found that OTUs of Granulicella, Edaphorbacter, and 2 undescribed OTUs from the Acidobacteria subgroup 2 being significant to Central Texas fungal samples (Fig. 5a). Similarly, regional differences among the Actinobacteria were driven by five OTUs, with Nocardioides, Mycobacterium, and Corynebacterium in Central Texas fungus gardens and Intrasporangiaceae and Naumannella significant for East Texas fungal samples (Fig. 5b). Nine OTUs within Alphaproteobacteria were found to drive the differentiation of this community based on region, with some of these significant OTUs for the Central Texas fungal samples being associated with Caulobacteracea, Acetobacteraceae, Xanthobacteraceae, and Micropepsaceae (Fig. 5c). 4 OTUs within Gammaproteobacteria were found to drive regional community differentation, with OTUs within Ideonella, Enhydrobacter, and the Burkholderia-Caballeronia-Paraburkholderia complex significant for Central Texas fungal samples (Fig. 5d). Additionally, OTUs within Acidobacteriia and Alphaproteobacteria were found to significantly drive community differences of the three fungal lineages, but this significance was due to these driver OTUs being found primarily within the Clade B3 samples, which was relatively undersampled $(n=3)$ (Fig. S4a,b).

Comparing extrapolated rarefaction curves for fungus garden microbiomes (Mesoplasma excluded) show that Central Texas fungi contain significantly more OTUs in comparison to East Texas fungi (Fig. $6 a)$; the average Shannon's Diversity Index for Central Texas $(H=3.155)$ fungus was greater than that of East Texas $(H=2.151)$ fungus $(t=-2.1604, d f=13.524, p=0.049)$. Rarefaction curves of fungus garden microbiome based on host ant species showed no significant differences (Fig. 6b). Rarefaction curves based on fungal clade showed significant differences; with Clade B4 fungus having more expected OTUs than Clade B5 fungus (Fig. 6c). The similarity between the rarefaction curves of fungus grown by the different ant host species was also reflected in the Shannon's Diversity Index values for fungus grown by T. septentrionalis $(H=2.430)$ and $M$. turrifex $(H=2.459)(t=0.5936, d f=21.908, p=0.9532)$ (Fig. $6 d)$. However, there was not a statistical difference in the average Shannon's Diversity Index between Clade B3 $(H=3.033)$, Clade $B 4(H=2.581)$, and Clade $B 5(H=2.205)$ fungal samples $(F=0.608, d f=2, p=0.554)$ (Fig. 6e). 
Comparing extrapolated rarefaction curves for fungus garden microbiomes (Mesoplasma included) show that Central Texas fungi contain significantly more OTUs in comparison to East Texas fungi (Fig. S5a); the average Shannon's Diversity Index for Central Texas $(\mathrm{H}=3.058)$ fungus was greater than that of East Texas $(H=1.489)$ fungus $(t=-2.6417, d f=22, p=0.0149)$. Rarefaction curves of fungus garden microbiome based on host ant species showed no significant differences (Fig. S5b). Rarefaction curves based on fungal clade showed significant differences; with Clade B4 fungus having more expected OTUs than Clade B5 fungus (Fig. S5c). The similarity between the rarefaction curves of fungus grown by the different ant host species was also reflected in the Shannon's Diversity Index values for fungus grown by T. septentrionalis $(H=1.675)$ and M. turrifex $(H=2.268)(t=0.97297, d f=22, p=0.3411)$ (Fig. S5d). However, there was not a statistical difference in the average Shannon's Diversity Index between Clade B3 $(H=3.056)$, Clade $B 4(H=2.191)$, and Clade $B 5(H=1.659)$ fungal samples $(F=1.188, d f=2, p=0.325)$ (Fig. S5e). In summary, Mesoplasma did not appear to influence overall diversity patterns.

\section{Discussion}

The most significant finding in this study is that different processes appear to structure the bacterial microbiomes of the fungus-gardening ant symbiosis. Each ant species had a unique bacterial microbiome, whereas fungal lineage appeared to have little to no role in structuring the bacterial microbiome of the fungus garden. This study, along with another that compared five additional attine species (Ronque et al., 2020) provides more evidence that individual ant species possess unique bacterial microbiomes. Unlike an earlier report that found similarities of bacterial microbiome structure in the ants and fungus gardens of the attine Mycocepurus smithii, fungus gardens of $T$. septentrionalis and $M$. turrifex possess bacterial microbiomes that are very distinct from their host ant species (Kellner et al., 2015). Other than OTUs of two bacterial classes (Acidobacteria and Alphaproteobacteria) associated with fungus gardens that appeared to segregate among fungal lineages and the two ant species, there appeared to be few if any bacteria that could be codispersed with the fungus (Table 4). The bacterial microbiome of the fungus garden had a lesser defined structure that may in part be determined by the environment.

The ant associated bacterial microbiomes were very distinct. While $T$. septentrionalis and $M$. turrifex had a high abundance of Actinobacteria as part of their microbiome, the taxonomic identity of these bacteria differed between the two species. Mycetomoellerius turrifex ant microbiome was characterized by Actinobacteria in the genera Pseudonocardia and Amycolatopsis, whereas the ant microbiome of $T$. septentrionalis was characterized by Ponticoccus and Microlunatus. Additionally, T. septentrionalis appeared to have an extensive coverage of of Solirubrobacter. The function of Solirubrobacter is unknown, however, it has been reported in soil crust (Reddy \& Garcia-Pichel, 2009), agricultural soils (Kim et al., 2007), and earthworm burrows (Singleton et al., 2003). Actinobacteria are commonly known to produce antibiotic and are commonly seen in fungus-gardening ants and other insects where they are thought to serve as defensive symbionts (Kaltenpoth et al., 2005; Fernández-Marín et al., 2009; Kaltenpoth, 2009). For example, Actinobacteria are thought to be part of a generalized defense against Escovopsis pathogens (Currie et al., 2003; Li et al., 2018). Considering the overall differences in ant 
microbiome structure and the differences in indicator species, it would appear that each species has either 1) a different strategy of dealing with pathogens or 2) experiences different pathogens altogether. The identity of pathogens in either population is largely unknown and unexplored, though studies on other attines have shown that different attine taxa can share the same or similar pathogens (Gerardo et al., 2006; Kellner et al., 2018).

Assuming that the significant ant species effect of ant bacterial microbiomes is an outcome of vertical transmission, the contrasting microbiomes found in T. septentrionalis and M. turrifex could reflect different phylogeographic histories. The relative uniformity of bacterial communities associated with $T$. septentrionalis ants could reflect low diversity from recent population expansion or strong purifying selection of microbial consortia, whereas the high variation among $M$. turrifex ant microbiomes could be due to relaxed selection on bacterial consortia and/or high diversity due to an ant population expansion that happened in the more distant past. The genetic diversity of $T$. septentrionalis ants is generally low in Texas (and lowest in Central Texas), which likely represents recent expansion, a conclusion supported by mtDNA, microsatellites and genotyping-by-sequencing approaches (Seal et al., 2015; Matthews et al., 2020).

Variation in ant species microbiomes may involve responses to stress, since stress is thought to structure microbiomes (Zaneveld et al., 2017; Howe-Kerr et al., 2020; Medina et al., 2022). For example, microbiomes may become more variable in stressful environments as hosts lose control over their symbionts or variable microbiome structure may be a mechanism to deal with environmental stress (Medina et al., 2022). The region studied (east and central Texas) encompasses the eastern and western range limits of $M$. turrifex and $T$. septentrionalis. Recent distribution models indicated that different variables predicted their respective distributions; for example, the $M$. turrifex distribution was explained by annual mean temperature whereas $T$. septentrionalis was predicted by winter precipitation (Senula et al., 2019). How the microbiomes react to these environmental variables remains unknown, but could be explored experimentally by exposing ant colonies to temperature or humidity stress.

Interestingly, we found very little support that each ant species are structuring the microbiome of their fungus gardens, since the gardens of each species were not different from one another in terms of their associated bacterial community. This is surprising, considering the differences in ant-associated Actinobacteria, which hypothetically would produce different secondary metabolites (van der Meij et al., 2017; Batey et al., 2020; Goldstein \& Klassen, 2020) that could in turn influence the abundances of other bacterial taxa. One possible explanation is that regions could differ in plant communities and thus the types of substrates the ants are feeding the garden (de Fine Licht \& Boomsma, 2010; De Fine Licht \& Boomsma, 2014; Seal et al., 2014). While there were significant differences among the OTU's encountered in each region, most belonged to the same bacterial taxa (e.g., Actinobacteria or Acidobacteria, Table 3 , S2), which suggests common mechanisms in the acquisition of these bacteria and some genetic differences among bacteria that could be explained by dispersal limitation. A previous study examined the ant and fungal microbiome of $M$. smithii and discovered that the fungal microbiome was influenced by the environment rather than the fungal lineage, which suggested that the ants were actively acquiring 
bacteria from the environment (Kellner et al., 2015). As a result, most of the impact of ant species or fungal lineage could be obscured by fungal substrates and environments.

This study along with others (Sapountzis et al., 2015; Meirelles et al., 2016; Sapountzis et al., 2019) revealed that Mesoplasma to be common in ants and fungus gardens, yet variation in Mesoplasma (or Enterbacteriales, generally) was not a significant predictor or microbiome structure or ant host, fungus garden or region. Phylogenetic analyses suggest that there are attine specialized Mesoplasma distinct from army ant Mesoplasma, but the resolution of standard Illumina reads appears to be too low to warrant interspecific comparisons among attine species (Meirelles et al., 2016). The function of Mesoplasma remains unknown, but it might contribute to colony mortality, it might be opportunistic, or it might be a permanent mutualist or a context-dependent mutualist (Sapountzis et al., 2015).

\section{Conclusion}

This study has shown that two distantly related, co-occurring fungus gardening ant species possess complex microbiomes that are acquired by different mechanisms. Much of the ant associated microbiome is presumably inherited due to the strong ant-host signal, whereas the most of the bacterial microbiome of the fungus garden appears to be acquired from the environment. A limitation of the current study is that it did not incorporate intraspecific molecular markers (i.e., within host or fungus garden lineage); as a result, this study did not possess the power to explicitly test for possible 'phylosymbiosis' of ant or ant-fungus and bacterial symbionts, which predicts phylogenetic concordance among hosts and symbionts (Lim \& Bordenstein, 2020; Trevelline et al., 2020). Two distinct processes could determine the apparent species-specific ant microbiome. Bacteria could be inherited vertically via founding queens, which would explain the strong cophylogenetic signal between ants and Pseudonocardia bacteria (Cafaro et al., 2011). On the other hand, the species specific effect we report here could also be explained by horizontal transmission if ants are actively acquiring bacteria in a species specific manner (Mueller et al., 2010). As a result, while there is a strong ant species effect driving microbiome structure, some of this pattern could result from behavioral differences where the ants selectively acquire bacterial lineages over others. Therefore, the comparison of $M$. turrifex and $T$. septentrionalis may be somewhat crude and may overemphasize coevolutionary signals, considering the large genetic distances between these two species (Solomon et al 2019). Future studies should compare microbiomes of closely related species, such as those found in western North America and the northern Neotropics (Solomon et al., 2019; Beigel et al., 2021) and employ intraspecific genetic markers (Matthews et al., 2020; Beigel et al., 2021; Matthews et al., 2021). Moreover, co-phylogenetic concordance does not necessarily imply coevolution/coadaptation (Douglas, 2010). To discriminate among the latter, cross-fostering experiments (switching host ants onto novel fungi; (Seal \& Mueller, 2014; Seal et al., 2014)) could demonstrate whether fungal associated (e.g., Acidobacteria and Alphaproteobacteria, Table 4) are adapted to certain hosts.

\section{Statements And Declarations}




\section{Funding}

Funding was provided by the National Science Foundation IOS-1552822 to JNS and DEB-1354629 to KK). Additional funding and logistic support was provided by Texas Ecolab (https://texasecolabprogram.org/).

\section{Competing Interests}

The authors have no relevant financial or non-financial interests to disclose.

\section{Author Contributions}

All authors contributed to the study conception and design. Material preparation, data collection and analysis were performed by Mattea Allert, Blake Bringhurst, Matthew Greenwold, Katrin Kellner, and Jon Seal. The manuscript was written by Mattea Allert, Blake Bringhurst, and Jon Seal. All authors read and approved the final manuscript.

\section{Data Availability}

Raw microbiome sequences for all samples have been uploaded to NCBI under the BioProject PRJNA789907. Fungal ITS sequences from all applicable fungal garden samples have been uploaded to GenBank, with accession numbers found in Table 1. Our Qiime2 pipeline, along with sample R script used during the post-processing analysis, can be found at https://github.com/bsbringhurst/TS-and-MTMicrobiome-Files. The resulting OTU table output by our Qiime2 pipeline can be found in the DRYAD Digital Repository at https://doi.org/10.5061/dryad.7wm37pvv1.

\section{Acknowledgments}

We thank Joshua Banta, Neil Ford and Kate Hertweck for constructive criticisms on earlier drafts of this manuscript. Ant collections and fungal genotyping were assisted by Leighanna Mindt and Joseph Luiso.

\section{References}

1. Aylward, F.O., Burnum, K.E., Scott, J.J., Suen, G., Tringe, S.G., Adams, S.M., Barry, K.W., Nicora, C.D., Piehowski, P.D., Purvine, S.O., Starrett, G.J., Goodwin, L.A., Smith, R.D., Lipton, M.S. \& Currie, C.R. (2012) Metagenomic and metaproteomic insights into bacterial communities in leaf-cutter ant fungus gardens. ISME J, 6, 1688-701.

2. Batey, S.F.D., Greco, C., Hutchings, M.I. \& Wilkinson, B. (2020) Chemical warfare between fungusgrowing ants and their pathogens. Current Opinion in Chemical Biology, 59, 172-181.

3. Beigel, K., Matthews, A.E., Kellner, K., Pawlik, C., Greenwold, M. \& Seal, J.N. (2021) Cophylogenetic analyses of ant-fungal specificity: 'One to one with some exceptions'. Molecular Ecology, 30, 56055620. 
4. Blüthgen, N., Gebauer, G. \& Fiedler, K. (2003) Disentangling a rainforest food web using stable isotopes: dietary diversity in a species-rich ant community. Oecologia, 137, 426-435.

5. Bokulich, N.A., Kaehler, B.D., Rideout, J.R., Dillon, M., Bolyen, E., Knight, R., Huttley, G.A. \& Gregory Caporaso, J. (2018) Optimizing taxonomic classification of marker-gene amplicon sequences with QIIME 2's q2-feature-classifier plugin. Microbiome, 6, 90.

6. Bolyen, E., Rideout, J.R., Dillon, M.R., Bokulich, N.A., Abnet, C.C., Al-Ghalith, G.A., Alexander, H., Alm, E.J., Arumugam, M., Asnicar, F., Bai, Y., Bisanz, J.E., Bittinger, K., Brejnrod, A., Brislawn, C.J., Brown, C.T., Callahan, B.J., Caraballo-Rodríguez, A.M., Chase, J., Cope, E.K., Da Silva, R., Diener, C., Dorrestein, P.C., Douglas, G.M., Durall, D.M., Duvallet, C., Edwardson, C.F., Ernst, M., Estaki, M., Fouquier, J., Gauglitz, J.M., Gibbons, S.M., Gibson, D.L., Gonzalez, A., Gorlick, K., Guo, J., Hillmann, B., Holmes, S., Holste, H., Huttenhower, C., Huttley, G.A., Janssen, S., Jarmusch, A.K., Jiang, L., Kaehler, B.D., Kang, K.B., Keefe, C.R., Keim, P., Kelley, S.T., Knights, D., Koester, I., Kosciolek, T., Kreps, J., Langille, M.G.I., Lee, J., Ley, R., Liu, Y.-X., Loftfield, E., Lozupone, C., Maher, M., Marotz, C., Martin, B.D., McDonald, D., Mclver, L.J., Melnik, A.V., Metcalf, J.L., Morgan, S.C., Morton, J.T., Naimey, A.T., Navas-Molina, J.A., Nothias, L.F., Orchanian, S.B., Pearson, T., Peoples, S.L., Petras, D., Preuss, M.L., Pruesse, E., Rasmussen, L.B., Rivers, A., Robeson, M.S., Rosenthal, P., Segata, N., Shaffer, M., Shiffer, A., Sinha, R., Song, S.J., Spear, J.R., Swafford, A.D., Thompson, L.R., Torres, P.J., Trinh, P., Tripathi, A., Turnbaugh, P.J., Ul-Hasan, S., van der Hooft, J.J.J., Vargas, F., Vázquez-Baeza, Y., Vogtmann, E., von Hippel, M., Walters, W., Wan, Y., Wang, M., Warren, J., Weber, K.C., Williamson, C.H.D., Willis, A.D., Xu, Z.Z., Zaneveld, J.R., Zhang, Y., Zhu, Q., Knight, R. \& Caporaso, J.G. (2019) Reproducible, interactive, scalable and extensible microbiome data science using QIIME 2. Nature Biotechnology, 37, 852-857.

7. Borm, S.v., Buschinger, A., Boomsma, J.J. \& Billen, J. (2002) Tetraponera ants have gut symbionts related to nitrogen-fixing root-nodule bacteria. Proceedings of the Royal Society of London. Series B: Biological Sciences, 269, 2023-2027.

8. Brown, J.J., Mihaljevic, J.R., Des Marteaux, L. \& Hrček, J. (2020) Metacommunity theory for transmission of heritable symbionts within insect communities. Ecology and Evolution, 10, 17031721.

9. Cáceres, M.D. \& Legendre, P. (2009) Associations between species and groups of sites: indices and statistical inference. Ecology, 90, 3566-3574.

10. Cafaro, M., Poulsen, M., Little, A.E.F., Price, S., Gerardo, N.M., Wong, B., Stuart, A.E., Larget, B., Abbot, P. \& Currie, C.R. (2011) Specificity in the symbiotic association between fungus-growing ants and protective Pseudonocardia bacteria. Proceedings of the Royal Society B, 278, 1814-1822.

11. Callahan, B.J., McMurdie, P.J., Rosen, M.J., Han, A.W., Johnson, A.J.A. \& Holmes, S.P. (2016) DADA2: High-resolution sample inference from Illumina amplicon data. Nature Methods, 13, 581-583.

12. Clay, K. (2014) Defensive-symbiosis: a microbial perspective. Functional Ecology, 28, 293-298.

13. Colwell, R.K. (2013) EstimateS: Statistical estimation of species richness and shared species from samples. . 
14. Currie, C.R., Bot, A.N.M. \& Boomsma, J.J. (2003) Experimental evidence of a tripartite mutualism: bacteria protect ant fungus gardens from specialized parasites. Oikos, 101, 91-102.

15. Davidson, D.W., Cook, S.C., Snelling, R.R. \& Chua, T.H. (2003) Explaining the abundance of ants in lowland tropical rainforest canopies. Science, 300, 969-72.

16. de Fine Licht, H. \& Boomsma, J. (2010) Forage collection, substrate preparation, and diet composition in fungus-growing ants. Ecological Entomology, 35, 259-269.

17. De Fine Licht, H.H. \& Boomsma, J.J. (2014) Variable interaction specificity and symbiont performance in Panamanian Trachymyrmex and Sericomyrmex fungus-growing ants. BMC Evol Biol, $14,244$.

18. Dheilly, N.M., Poulin, R. \& Thomas, F. (2015) Biological warfare: Microorganisms as drivers of hostparasite interactions. Infect Genet Evol,

19. Diggs, G.M., Lipscomb, B.L., Reed, M.D. \& O'Kennon, R.J. (2006) Illustrated Flora of East Texas, Volume One. Botanical Research Institute of Texas

20. Fort Worth, Texas.

21. Douglas, A.E. (2010) The Symbiotic Habit. Princeton University Press, Princeton, New Jersey.

22. Douglas, Angela E. (2011) Lessons from Studying Insect Symbioses. Cell Host \& Microbe, 10, 359367.

23. Douglas, A.E. (2014) Symbiosis as a general principle in eukaryotic evolution. Cold Spring Harbor Perspectives in Biology, doi: 10.1101/cshperspect.a016113

24. Douglas, A.E. (2015) Multiorganismal insects: diversity and function of resident microorganisms. Annu Rev Entomol, 60, 17-34.

25. Dowd, S.E., Callaway, T., Wolcott, R., Sun, Y., McKeehan, T., Hagevoort, R. \& Edrington, T. (2008) Evaluation of the bacterial diversity in the feces of cattle using $16 \mathrm{~S}$ rDNA bacterial gag-encoded FLX amplicon pyrosequencing (tTEFAP). BMC Microbiology, 8

26. Farji-Brener, A.G. \& Werenkraut, V. (2017) The effects of ant nests on soil fertility and plant performance: a meta-analysis. Journal of Animal Ecology, 86, 866-877.

27. Feldhaar, H. (2011) Bacterial symbionts as mediators of ecologically important traits of insect hosts. Ecological Entomology, 36, 533-543.

28. Fernández-Marín, H., Zimmerman, J.K., Nash, D.R., Boomsma, J.J. \& Wcislo, W.T. (2009) Reduced biological control and enhanced chemical pest management in the evolution of fungus farming in ants. Proceedings of the Royal Society B, 276, 2263-2269.

29. Francoeur, C.B., May, D.S., Thairu, M.W., Hoang, D.Q., Panthofer, O., Bugni, T.S., Pupo, M.T., Clardy, J., Pinto-Tomas, A.A. \& Currie, C.R. (2021) Burkholderia from Fungus Gardens of Fungus-Growing Ants Produces Antifungals That Inhibit the Specialized Parasite Escovopsis. Appl Environ Microbiol, 87, e0017821.

30. Garcia, J.R. \& Gerardo, N.M. (2014) The symbiont side of symbiosis: do microbes really benefit? Front Microbiol, 5, 510. 
31. Gerardo, N.M., Mueller, U.G. \& Currie, C.R. (2006) Complex host-pathogen coevolution in the Apterostigma fungus-growing ant-microbe symbiosis. BMC Evol Biol, 6, 88.

32. Goldstein, S.L. \& Klassen, J.L. (2020) Pseudonocardia Symbionts of Fungus-Growing Ants and the Evolution of Defensive Secondary Metabolism. Frontiers in microbiology, 11, 621041-621041.

33. Hambleton, E.A., Guse, A. \& Pringle, J.R. (2014) Similar specificities of symbiont uptake by adults and larvae in an anemone model system for coral biology. J Exp Biol, 217, 1613-9.

34. Hothorn, T., Bretz, F. \& Westfall, P. (2008) Simultaneous inference in general parametric models. Biom $J, 50,346-63$.

35. Howe-Kerr, L.I., Bachelot, B., Wright, R.M., Kenkel, C.D., Bay, L.K. \& Correa, A.M.S. (2020) Symbiont community diversity is more variable in corals that respond poorly to stress. Global Change Biology, 26, 2220-2234.

36. Hu, Y., Sanders, J.G., Łukasik, P., D’Amelio, C.L., Millar, J.S., Vann, D.R., Lan, Y., Newton, J.A., Schotanus, M., Kronauer, D.J.C., Pierce, N.E., Moreau, C.S., Wertz, J.T., Engel, P. \& Russell, J.A. (2018) Herbivorous turtle ants obtain essential nutrients from a conserved nitrogen-recycling gut microbiome. Nature Communications, 9, 964.

37. Ishak, H.D., Miller, J.L., Sen, R., Dowd, S.E., Meyer, E. \& Mueller, U.G. (2011) Microbiomes of ant castes implicate new microbial roles in the fungus-growing ant Trachymyrmex septentrionalis. Sci Rep, 1, 204.

38. Ješovnik, A., Sosa-Calvo, J., Lloyd, M.W., Branstetter, M.G., Fernández, F. \& Schultz, T.R. (2017) Phylogenomic species delimitation and host-symbiont coevolution in the fungus-farming ant genus Sericomyrmex Mayr (Hymenoptera: Formicidae): ultraconserved elements (UCEs) resolve a recent radiation. Systematic Entomology, 42, 523-542.

39. Johansson, H., Dhaygude, K., Lindström, S., Helanterä, H., Sundström, L. \& Trontti, K. (2013) A metatranscriptomic approach to the identification of microbiota associated with the ant Formica exsecta. PLOS ONE, 8, e79777.

40. Kaltenpoth, M. (2009) Actinobacteria as mutualists: general healthcare for insects? Trends in Microbiology, 17, 529-535.

41. Kaltenpoth, M. \& Engl, T. (2013) Defensive microbial symbionts in Hymenoptera. Functional Ecology, 28, 315-327.

42. Kaltenpoth, M., Göttler, W., Herzner, G. \& Strohm, E. (2005) Symbiotic bacteria protect wasp larvae from fungal infection. Current Biology, 15, 475-479.

43. Kearse, M.M., R., Wilson, A., Stones-Havas, S., Cheung, M., Sturrock, S., Buxton, S., Cooper, A., Markowitz, S., Duran, C., Thierer, T., Ashton, B., Mentjies, P. \& Drummond, A. (2012) Geneious Basic: an integrated and extendable desktop software platform for the organization and analysis of sequence data. Bioinformatics, 28, 1647-1649.

44. Kellner, K., Ishak, H.D., Linksvayer, T.A. \& Mueller, U.G. (2015) Bacterial community composition and diversity in an ancestral ant fungus symbiosis. FEMS Microbiol Ecol, 91 
45. Kellner, K., Kardish, M.R., Seal, J.N., Linksvayer, T.A. \& Mueller, U.G. (2018) Symbiont-Mediated HostParasite Dynamics in a Fungus-Gardening Ant. Microb Ecol, 76, 530-543.

46. Kim, M.K., Na, J.-R., Lee, T.-H., Im, W.-T., Soung, N.-K. \& Yang, D.-C. (2007) Solirubrobacter soli sp. nov., isolated from soil of a ginseng field. International Journal of Systematic and Evolutionary Microbiology, 57, 1453-1455.

47. King, J.R., Warren, R.J. \& Bradford, M.A. (2013) Social insects dominate eastern US temperate hardwood forest macroinvertebrate communities in warmer regions. PLoS One, 8, e75843.

48. Klassen, J.L. (2019) Ecology helps bound causal explanations in microbiology. Biology \& Philosophy, $35,3$.

49. Klepzig, K.D., Adams, A.S., Handelsman, J. \& Raffa, K.F. (2009) Symbioses: A key driver of insect physiological processes, ecological interactions, evolutionary diversification, and impacts on Humans. Enviromental Entomology, 38, 67-77.

50. Li, H., Sosa-Calvo, J., Horn, H.A., Pupo, M.T., Clardy, J., Rabeling, C., Schultz, T.R. \& Currie, C.R. (2018) Convergent evolution of complex structures for ant-bacterial defensive symbiosis in fungus-farming ants. Proceedings of the National Academy of Sciences, 115, 10720-10725.

51. Lim, S.J. \& Bordenstein, S.R. (2020) An introduction to phylosymbiosis. Proceedings of the Royal Society B: Biological Sciences, 287, 20192900.

52. Little, A.E.F. \& Currie, C.R. (2008) Black yeast symbionts compromise the efficiencey of antibiotic defenses in fungus-growing ants. Ecology, 89, 1216-1222.

53. Luiso, J., Kellner, K., Matthews, A.E., Mueller, U.G. \& Seal, J.N. (2020) High diversity and multiple invasions to North America by fungi grown by the northern-most Trachymyrmex and Mycetomoellerius ant species. Fungal Ecology, 44, 100878.

54. Matthews, A.E., Kellner, K. \& Seal, J.N. (2021) Male-biased dispersal in a fungus-gardening ant symbiosis. Ecology and Evolution, 11, 2307-2320.

55. Matthews, A.E., Rowan, C., Stone, C., Kellner, K. \& Seal, J.N. (2020) Development, characterization, and cross-amplification of polymorphic microsatellite markers for North American Trachymyrmex and Mycetomoellerius ants. BMC Research Notes, 13, 173.

56. McFall-Ngai, M., Hadfield, M.G., Bosch, T.C., Carey, H.V., Domazet-Loso, T., Douglas, A.E., Dubilier, N., Eberl, G., Fukami, T., Gilbert, S.F., Hentschel, U., King, N., Kjelleberg, S., Knoll, A.H., Kremer, N., Mazmanian, S.K., Metcalf, J.L., Nealson, K., Pierce, N.E., Rawls, J.F., Reid, A., Ruby, E.G., Rumpho, M., Sanders, J.G., Tautz, D. \& Wernegreen, J.J. (2013) Animals in a bacterial world, a new imperative for the life sciences. Proc Natl Acad Sci U S A, 110, 3229-36.

57. Medina, M., Baker, D.M., Baltrus, D.A., Bennett, G.M., Cardini, U., Correa, A.M.S., Degnan, S.M., Christa, G., Kim, E., Li, J., Nash, D.R., Marzinelli, E., Nishiguchi, M., Prada, C., Roth, M.S., Saha, M., Smith, C.I., Theis, K.R. \& Zaneveld, J. (2022) Grand Challenges in Coevolution. Frontiers in Ecology and

\section{Evolution, 9}

58. Meirelles, L.A., Mendes, T.D., Solomon, S.E., Bueno, O.C., Pagnocca, F.C. \& Rodrigues, A. (2014) Broad Escovopsis-inhibition activity of Pseudonocardia associated with Trachymyrmex ants. 
Environmental Microbiology Reports, 6, 339-345.

59. Meirelles, L.A., McFrederick, Q.S., Rodrigues, A., Mantovani, J.D., de Melo Rodovalho, C., Ferreira, H., Bacci Jr, M. \& Mueller, U.G. (2016) Bacterial microbiomes from vertically transmitted fungal inocula of the leaf-cutting ant Atta texana. Environmental Microbiology Reports, 8, 630-640.

60. Mikheyev, A.S., Mueller, U.G. \& Boomsma, J.J. (2007) Population genetic signatures of diffuse coevolution between leaf-cutting ants and their cultivar fungi. Mol Ecol, 16, 209-16.

61. Mikheyev, A.S., Vo, T.L. \& Mueller, U.G. (2008) Phylogeography of post-Pleistocene population expansion in a fungus-gardening ant and its microbial mutualists. Molecular Ecology, 17, 4480-4488.

62. Montoya, Q.V., Martiarena, M.J.S., Bizarria Jr, R., Gerardo, N.M. \& Rodrigues, A. (2021) Fungi inhabiting attine ant colonies: reassessment of the genus Escovopsis and description of Luteomyces and Sympodiorosea gens. nov. IMA Fungus, 12, 23.

63. Moore, G.W., Edgar, C.B., Vogel, J.G., Washington-Allen, R.A., March, Rosaleen G. \& Zehnder, R. (2016) Tree mortality from an exceptional drought spanning mesic to semiarid ecoregions. Ecological Applications, 26, 602-611.

64. Moran, N.A. (2001) Bacterial menageries inside insects. Proc Natl Acad Sci U S A, 98, 1338-40.

65. Mueller, U., Kardish, M., Ishak, H., Wright, A., Solomon, S., Bruschi, S., Carlson, A. \& Bacci, M. (2018) Phylogenetic patterns of ant-fungus associations indicate that farming strategies, not only a superior fungal cultivar, explain the ecological success of leafcutter ants. Molecular Ecology, 27, 2414-2434.

66. Mueller, U.G., Ishak, H., Lee, J.C., Sen, R. \& Gutell, R.R. (2010) Placement of attine ant-associated Pseudonocardia in a global Pseudonocardia phylogeny (Pseudonocardiaceae, Actinomycetales): a test of two symbiont-association models. Antonie Van Leeuwenhoek, 98, 195-212.

67. Neuvonen, M.-M., Tamarit, D., Näslund, K., Liebig, J., Feldhaar, H., Moran, N.A., Guy, L. \& Andersson, S.G.E. (2016) The genome of Rhizobiales bacteria in predatory ants reveals urease gene functions but no genes for nitrogen fixation. Scientific Reports, 6, 39197.

68. Oksanen, J., Blanchet, G., Friendly, M., Kindt, R., Legendre, P., McGlinn, D., Minchin, P.R., O'Hara, R.B., Simpson, G.L., Solymos, P., Stevens, M.H.H., Szoecs, E. \& Wagner, H. (2018) vegan: community ecology package. R package version 2.4-6.

69. Osti, J.F. \& Rodrigues, A. (2018) Escovopsioides as a fungal antagonist of the fungus cultivated by leafcutter ants. BMC Microbiology, 18, 130.

70. Parfrey, L.W., Moreau, C.S. \& Russell, J.A. (2018) Introduction: The host-associated microbiome: Pattern, process and function. Molecular Ecology, 27, 1749-1765.

71. Parr, C.L., Eggleton, P., Davies, A.B., Evans, T.A. \& Holdsworth, S. (2016) Suppression of savanna ants alters invertebrate composition and influences key ecosystem processes. Ecology, 97, 1611-1617.

72. Pinto-Tomás, A.A., Anderson, M., Suen, G., Stevenson, D., Cleland, W., Weimer, P. \& Currie, C.R. (2009) Symbiotic nitrogen fixation in the fungus gardens of leaf-cutter ants. Science, 326, 1120-1123. 
73. Quast, C., Pruesse, E., Yilmaz, P., Gerken, J., Schweer, T., Yarza, P., Peplies, J. \& Glöckner, F.O. (2013) The SILVA ribosomal RNA gene database project: improved data processing and web-based tools. Nucleic acids research, 41, D590-D596.

74. Rabeling, C., Cover, S.P., Johnson, R.A. \& Mueller, U.G. (2007) A review of the North American species of the fungus-gardening ant genus Trachymyrmex (Hymenoptera: Formicidae). Zootaxa, 1664, 1-53.

75. Reddy, G.S.N. \& Garcia-Pichel, F. (2009) Description of Patulibacter americanus sp. nov., isolated from biological soil crusts, emended description of the genus Patulibacter Takahashi et al. 2006 and proposal of Solirubrobacterales ord. nov. and Thermoleophilales ord. nov. International Journal of Systematic and Evolutionary Microbiology, 59, 87-94.

76. Rodrigues, A., Cable, R.N., Mueller, U.G., Bacci, M., Jr. \& Pagnocca, F.C. (2009) Antagonistic interactions between garden yeasts and microfungal garden pathogens of leaf-cutting ants. Antonie Van Leeuwenhoek, 96, 331-42.

77. Rodrigues, A., Mueller, U.G., Ishak, H.D., Bacci, M., Jr. \& Pagnocca, F.C. (2011) Ecology of microfungal communities in gardens of fungus-growing ants (Hymenoptera: Formicidae): a year-long survey of three species of attine ants in Central Texas. FEMS Microbiol Ecol, 78, 244-55.

78. Ronque, M.U.V., Lyra, M.L., Migliorini, G.H., Bacci, M. \& Oliveira, P.S. (2020) Symbiotic bacterial communities in rainforest fungus-farming ants: evidence for species and colony specificity. Scientific Reports, 10, 10172.

79. Sapountzis, P., Nash, D.R., Schiøtt, M. \& Boomsma, J.J. (2019) The evolution of abdominal microbiomes in fungus-growing ants. Molecular Ecology, 28, 879-899.

80. Sapountzis, P., Zhukova, M., Hansen, L.H., Sorensen, S.J., Schiott, M. \& Boomsma, J.J. (2015) Acromyrmex Leaf-Cutting Ants Have Simple Gut Microbiota with Nitrogen-Fixing Potential. App/ Environ Microbiol, 81, 5527-37.

81. Schultz, T.R. \& Brady, S.G. (2008) Major evolutionary transitions in ant agriculture. Proceedings of the National Academy of Science, USA, 105, 5435-5440.

82. Schultz, T.R., Sosa-Calvo, J., Brady, S.G., Lopes, C.T., Mueller, U.G., Bacci, M., Jr. \& Vasconcelos, H.L. (2015) The most relictual fungus-farming ant species cultivates the most recently evolved and highly domesticated fungal symbiont species. American Naturalist, 185, 693-703.

83. Seal, J.N. \& Mueller, U.G. (2014) Instability of novel ant-fungal associations suggest that microbial interactions constrain horizontal transfer in higher fungus-gardening ants. Evolutionary Ecology, 28, 157-176.

84. Seal, J.N., Schiøtt, M. \& Mueller, U.G. (2014) Ant-fungal species combinations engineer physiological activity of fungus gardens. Journal of Experimental Biology, 217, 2540-2547.

85. Seal, J.N., Thiebaud, J. \& Mueller, U.G. (2015) Gone to Texas: comparative phylogeography of two Trachymyrmex species along the southeastern coastal plain of North America. Biological Journal of the Linnean Society, 114, 689-698.

86. Senula, S.F., Scavetta, J.T., Banta, J.A., Mueller, U.G., Seal, J.N. \& Kellner, K. (2019) Potential Distribution of Six North American Higher-Attine Fungus-Farming Ant (Hymenoptera: Formicidae) 
Species. Journal of Insect Science, 19, 1-11.

87. Silverstein, R.N., Correa, A.M. \& Baker, A.C. (2012) Specificity is rarely absolute in coral-algal symbiosis: implications for coral response to climate change. Proc Biol Sci, 279, 2609-18.

88. Singleton, D.R., Furlong, M.A., Peacock, A.D., White, D.C., Coleman, D.C. \& Whitman, W.B. (2003) Solirubrobacter pauli gen. nov., sp. nov., a mesophilic bacterium within the Rubrobacteridae related to common soil clones. International Journal of Systematic and Evolutionary Microbiology, 53, 485490.

89. Solomon, S.E., Rabeling, C., Sosa-Calvo, J., Lopes, C.T., Rodrigues, A., Vasconcelos, H.L., Bacci, M., Mueller, U.G. \& Schultz, T.R. (2019) The molecular phylogenetics of Trachymyrmex Forel ants and their fungal cultivars provide insights into the origin and coevolutionary history of 'higher-attine' ant agriculture. Systematic Entomology, 44, 939-956.

90. Swanson, A.C., Schwendenmann, L., Allen, M.F., Aronson, E.L., Artavia-León, A., Dierick, D., FernandezBou, A.S., Harmon, T.C., Murillo-Cruz, C., Oberbauer, S.F., Pinto-Tomás, A.A., Rundel, P.W. \& Zelikova, T.J. (2019) Welcome to the Atta world: A framework for understanding the effects of leaf-cutter ants on ecosystem functions. Functional Ecology, DOI: 10.1111/1365-2435.13319

91. Trevelline, B.K., Sosa, J., Hartup, B.K. \& Kohl, K.D. (2020) A bird's-eye view of phylosymbiosis: weak signatures of phylosymbiosis among all 15 species of cranes. Proceedings of the Royal Society $B$ : Biological Sciences, 287, 20192988.

92. Van Arnam, E.B., Currie, C.R. \& Clardy, J. (2018) Defense contracts: molecular protection in insectmicrobe symbioses. Chemical Society Reviews, 47, 1638-1651.

93. van der Meij, A., Worsley, S.F., Hutchings, M.I. \& van Wezel, G.P. (2017) Chemical ecology of antibiotic production by actinomycetes. FEMS Microbiology Reviews, 41, 392-416.

94. White, T., Bruns, T., Lee, S. \& Taylor, J. (1990) Amplification and direct sequencing of fungal ribosomal RNA genes for phylogenetics. PCR Protocols: a guide to methods and applications (ed. by M. Innis, D. Gelfand, J. Sninsky and T. White), pp. 315-322. Academic Press, San Diego.

95. Woyke, T., Teeling, H., Ivanova, N.N., Huntemann, M., Richter, M., Gloeckner, F.O., Boffelli, D., Anderson, I.J., Barry, K.W., Shapiro, H.J., Szeto, E., Kyrpides, N.C., Mussmann, M., Amann, R., Bergin, C., Ruehland, C., Rubin, E.M. \& Dubilier, N. (2006) Symbiosis insights through metagenomic analysis of a microbial consortium. Nature, 443, 950-955.

96. Yilmaz, P., Parfrey, L.W., Yarza, P., Gerken, J., Pruesse, E., Quast, C., Schweer, T., Peplies, J., Ludwig, W. \& Glöckner, F.O. (2014) The SILVA and "All-species Living Tree Project (LTP)" taxonomic frameworks. Nucleic acids research, 42, D643-D648.

97. Zaneveld, J.R., McMinds, R. \& Vega Thurber, R. (2017) Stress and stability: applying the Anna Karenina principle to animal microbiomes. Nature Microbiology, 2, 17121.

\section{Tables}


Table 1 Collection locations, species and fungal clade and Genbank Accession numbers of the fungus garden genotypes used in this study. 


\begin{tabular}{|c|c|c|c|c|c|}
\hline ID & Locality Name & $\begin{array}{l}\text { Texas } \\
\text { Region }\end{array}$ & Ant Species & $\begin{array}{l}\text { Fungal } \\
\text { Clade }\end{array}$ & $\begin{array}{l}\text { Genbank } \\
\text { Accession }\end{array}$ \\
\hline${ }_{1}^{\text {JNS160521- }}$ & Red Rock & Central & T.septentrionalis & B3 & MK142454 \\
\hline $\begin{array}{l}\text { JNS160521- } \\
2\end{array}$ & Red Rock & Central & T.septentrionalis & B4 & MK142349 \\
\hline $\begin{array}{l}\text { JNS160521- } \\
3\end{array}$ & Red Rock & Central & T.septentrionalis & B4 & MK142350 \\
\hline $\begin{array}{l}\text { JNS160522- } \\
2\end{array}$ & Stengl & Central & T.septentrionalis & B4 & MK142369 \\
\hline $\begin{array}{l}\text { JNS160522- } \\
3\end{array}$ & Stengl & Central & T.septentrionalis & B4 & MK142371 \\
\hline $\begin{array}{l}\text { JNS160523- } \\
1\end{array}$ & Gladewater & Eastern & T.septentrionalis & B4 & MK142354 \\
\hline $\begin{array}{l}\text { JNS160523- } \\
3\end{array}$ & Gladewater & Eastern & T.septentrionalis & B4 & MK142347 \\
\hline JNS160524 & Gladewater & Eastern & T.septentrionalis & * & Not Genotyped \\
\hline${ }_{1}^{J N S 160531-}$ & $\begin{array}{l}\text { UT Tyler } \\
\text { Forest }\end{array}$ & Eastern & T.septentrionalis & B4 & MK142355 \\
\hline $\begin{array}{l}\text { JNS160531- } \\
2\end{array}$ & $\begin{array}{l}\text { UT Tyler } \\
\text { Forest }\end{array}$ & Eastern & T.septentrionalis & B5 & MK142365 \\
\hline${ }_{3}^{J N S 160531-}$ & $\begin{array}{l}\text { UT Tyler } \\
\text { Forest }\end{array}$ & Eastern & T.septentrionalis & B5 & MK142366 \\
\hline $\begin{array}{l}\text { KK160530- } \\
4\end{array}$ & $\begin{array}{l}\text { Cherokee } \\
\text { county }\end{array}$ & Eastern & T.septentrionalis & B5 & MK142353 \\
\hline KK160530-2 & Brownsboro & Eastern & T.septentrionalis & B5 & MK142360 \\
\hline $\begin{array}{l}\text { JNS160414- } \\
1\end{array}$ & $\begin{array}{l}\text { UT Tyler } \\
\text { Forest }\end{array}$ & Eastern & M. turrifex & B5 & MK142458 \\
\hline $\begin{array}{l}\text { JNS160510- } \\
1\end{array}$ & $\begin{array}{l}\text { UT Tyler } \\
\text { Forest }\end{array}$ & Eastern & M. turrifex & B5 & MK142475 \\
\hline${ }_{1}^{J N S 160515-}$ & $\begin{array}{l}\text { UT Tyler } \\
\text { Forest }\end{array}$ & Eastern & M. turrifex & B5 & MK142474 \\
\hline${ }_{1}^{\text {JNS160521- }}$ & Red Rock & Central & M. turrifex & B3 & MK142454 \\
\hline${ }_{2}^{\text {JNS160521- }}$ & Rosanky & Central & M. turrifex & B4 & MK142373 \\
\hline JNS160525- & Henderson 2 & Eastern & M. turrifex & B5 & MK142459 \\
\hline
\end{tabular}




\begin{tabular}{|llllll|}
\hline 1 & & & & \\
\hline $2 N$ N160525- & Henderson 2 & Eastern & M. turrifex & B5 & MK142455 \\
\hline $\begin{array}{l}\text { JNS160525- } \\
3\end{array}$ & Henderson 2 & Eastern & M. turrifex & B5 & MK142460 \\
$\begin{array}{l}\text { KK160530- } \\
1\end{array}$ & $\begin{array}{l}\text { Cherokee } \\
\text { county }\end{array}$ & Eastern & M. turrifex & B5 & MK142456 \\
$\begin{array}{l}\text { KK160530- } \\
2\end{array}$ & $\begin{array}{l}\text { Cherokee } \\
\text { county }\end{array}$ & Eastern & M. turrifex & B5 & MK142457 \\
\hline $\begin{array}{l}\text { KK160530- } \\
3\end{array}$ & $\begin{array}{l}\text { Cherokee } \\
\text { county }\end{array}$ & Eastern & M. turrifex & B3 & MK142361 \\
\hline
\end{tabular}

Table 2 OTUs with greater than 1\% frequency for (A.) T. septentrionalis, and (B.) M. turrifex ant samples

A

\begin{tabular}{|lll|}
\hline Sample Type & OTU (Class - OTU) & Percentage \\
\hline T. septentrionalis Ants & Thermoleophilia - Solirubrobacter Strain 1 & $29.409 \%$ \\
\hline & Gammaproteobacteria - Luteimonas & $15.811 \%$ \\
\hline & Gammaproteobacteria - Unknown Burkholderiaceae & $9.209 \%$ \\
\hline Actinobacteria - Naumannella & $8.454 \%$ \\
\hline Actinobacteria - Unknown Intrasporangiaceae & $8.312 \%$ \\
\hline Mollicutes - Mesoplasma & $5.609 \%$ \\
\hline Alphaproteobacteria - Wolbachia & $5.102 \%$ \\
\hline Actinobacteria - Unknown Microbacteriaceae & $4.337 \%$ \\
\hline Thermoleophilia - Solirubrobacter Strain 2 & $3.938 \%$ \\
\hline Actinobacteria - Microlunatus & $2.213 \%$ \\
\hline Actinobacteria - Aeromicrobium & $1.816 \%$ \\
\hline Actinobacteria - Luteipulveratus & $1.330 \%$ \\
\hline
\end{tabular}

B 


\begin{tabular}{|lll|}
\hline Sample Type & OTU (Class - OTU) & Percentage \\
\hline M. turrifex Ants & Actinobacteria - Amycolatopsis & $19.814 \%$ \\
& Gammaproteobacteria - Unknown Burkholderiaceae & $14.633 \%$ \\
\hline & Actinobacteria - Unknown Microbacteriaceae & $10.530 \%$ \\
\hline Mollicutes - Mesoplasma & $7.988 \%$ \\
\hline Actinobacteria - Luteipulveratus & $7.145 \%$ \\
\hline Mollicutes - Spiroplasma & $6.277 \%$ \\
\hline Gammaproteobacteria - Noviherbaspirillum & $5.505 \%$ \\
\hline Actinobacteria - Pseudonocardia Strain 1 & $4.143 \%$ \\
\hline Alphaproteobacteria - Wolbachia & $3.372 \%$ \\
\hline Gammaproteobacteria - Luteimonas & $3.197 \%$ \\
\hline Actinobacteria - Unknown Intrasporangiaceae & $2.695 \%$ \\
\hline Actinobacteria - Pseudonocardia Strain 2 & $1.617 \%$ \\
\hline Bacteroidia - Niabella & $1.019 \%$ \\
\hline
\end{tabular}

Table 3 The top 5 OTUs with the highest indicator values (IV) for (A.) T. septentrionalis ant, (B.) M. turrifex ant, (C.) East Texas fungus garden, and (D.) Central Texas fungus garden samples found using the indicator species analysis

\section{A}

\begin{tabular}{|llll|}
\hline Sample Type & OTU (Class - OTU) & IV & p-value \\
\hline T. septentrionalis Ants & Thermoleophilia - Solirubrobacter Strain 1 & 0.894 & 0.0001 \\
\cline { 2 - 3 } & Thermoleophilia - Solirubrobacter Strain 2 & 0.816 & 0.0001 \\
\hline & Actinobacteria - Ponticoccus & 0.806 & 0.0001 \\
\hline Actinobacteria - Unknown Intrasporangiaceae & 0.691 & 0.0005 \\
\hline Actinobacteria - Naumannella & 0.617 & 0.0001 \\
\hline
\end{tabular}

B 


\begin{tabular}{|llll|}
\hline Sample Type & OTU (Class - OTU) & IV & p-value \\
\hline M. turrifex Ants & Actinobacteria - Amycolatopsis & 0.539 & 0.0001 \\
& Actinobacteria - Pseudonocardia & 0.500 & 0.0001 \\
& Alphaproteobacteria - Unknown Sphingomonadaceae & 0.457 & 0.0300 \\
\hline & Actinobacteria - Cutibacterium & 0.456 & 0.0274 \\
\hline & Actinobacteria - Corynebacterium & 0.443 & 0.0287 \\
\hline
\end{tabular}

C

\begin{tabular}{|llll|}
\hline Sample Type & OTU (Class - OTU) & IV & p-value \\
\hline East Texas Fungus & Actinobacteria - Naumannella & 0.554 & 0.0119 \\
& Actinobacteria - Unknown Intrasporangiaceae & 0.517 & 0.0239 \\
\hline
\end{tabular}

D

\begin{tabular}{|llll|}
\hline Sample Type & OTU (Class (if applicable) - OTU) & IV & p-value \\
\hline Central Texas Fungus & Gammaproteobacteria - Enhydrobacter & 0.610 & 0.0028 \\
\hline & Actinobacteria - Corynebacterium & 0.588 & 0.0073 \\
\hline & Acidobacteriia - Unknown Acidobacteria & 0.575 & 0.0026 \\
\hline Saccharimonadia - Unknown Saccharimonadales & 0.556 & 0.0035 \\
\hline Verrucomicrobiae - Unknown Opitutaceae & 0.547 & 0.0033 \\
\hline
\end{tabular}

Table 4 Tests of significance of variation with bacterial classes associated with (A.) ant and (B.) fungus garden bacterial microbiomes. Significant $(a<0.05)$ are in bold. Degrees of freedom of ant species and region $=1$ whereas $\mathrm{df}=\mathbf{2}$ in Fungal clade. CCA was performed on Actinobacteria, Alphaproteobacteria and Gammaproteobacteria whereas RDA was performed on Bacteroidia and Acidobacteria (See methods) 
A.

\begin{tabular}{|l|l|l|l|}
\hline Taxon & Ant Species & Fungal Clade & Region \\
\hline Acidobacteria & $\mathrm{F}=1.846, \mathrm{p}=0.055$ & $\mathrm{~F}=2.318, \mathrm{p}=0.113$ & $\mathrm{~F}=1.126, \mathrm{p}=0.329$ \\
\hline Actinobacteria & $\mathbf{F}=\mathbf{7 . 9 3 3 ,}, \mathbf{p}<\mathbf{0 . 0 0 0 1}$ & $\mathrm{F}=0.5810, \mathrm{p}=0.913$ & $\mathrm{~F}=0.697 \mathrm{p}=0.715$ \\
\hline Alphaproteobacteria & $\mathbf{F}=\mathbf{3 . 4 2 0 ,} \mathbf{p}<\mathbf{0 . 0 0 0 1}$ & $\mathrm{F}=1.5537, \mathrm{p}=0.181$ & $\mathrm{~F}=1.0697 \quad \mathrm{p}=0.383$ \\
\hline Bacteroidia & $\mathrm{F}=0.6217, \mathrm{p}=0.539$ & $\mathrm{~F}=0.7599 \mathrm{p}=0.525$ & $\mathrm{~F}=0.3367 \mathrm{p}=0.796$ \\
\hline Gammaproteobacteria & $\mathbf{F}=\mathbf{3 . 1 4 4 ,} \mathbf{p}=\mathbf{0 . 0 0 0 4}$ & $\mathrm{F}=0.529, \mathrm{p}=0.784$ & $\mathrm{~F}=0.2872, \mathrm{p}=0.887$ \\
\hline
\end{tabular}

B.

\begin{tabular}{|l|l|l|l|}
\hline Taxon & Ant Species & Fungal Clade & Region \\
\hline Acidobacteria & $\mathrm{F}=1.456, \mathrm{p}=0.1500$ & $\mathbf{F}=\mathbf{3 . 2 2 1 3}, \mathbf{p}=\mathbf{0 . 0 1 6 2}$ & $\mathbf{F}=\mathbf{2 . 8 3 9 5 ,} \mathbf{p}=\mathbf{0 . 0 3 7 3}$ \\
\hline Actinobacteria & $\mathbf{F}=\mathbf{1 . 5 2 2 8 ,} \mathbf{p}=\mathbf{0 . 0 3 1 5}$ & $\mathrm{F}=1.4886, \mathrm{p}=0.058$ & $\mathrm{~F}=0.9488, \mathrm{p}=0.461$ \\
\hline Alphaproteobacteria & $\mathbf{F}=\mathbf{2 . 7 8 2 9 ,} \mathbf{p}<\mathbf{0 . 0 0 0 1}$ & $\mathbf{F}=\mathbf{1 . 9 1 2 7 ,} \mathbf{p}=\mathbf{0 . 0 0 0 6}$ & $\mathrm{F}=1.2292, \mathrm{p}=0.235$ \\
\hline Bacteroidia & $\mathrm{F}=0.9383, \mathrm{p}=0.443$ & $\mathrm{~F}=0.2981, \mathrm{p}=0.898$ & $\mathrm{~F}=1.3256, \mathrm{p}=0.253$ \\
\hline Gammaproteobacteria & $\mathbf{F}=\mathbf{2 . 0 7 0 7 , p}=\mathbf{0 . 0 0 0 3}$ & $\mathrm{F}=0.9232 . \mathbf{p}=0.539$ & $\mathrm{~F}=0.5533, \mathbf{p}=0.810$ \\
\hline
\end{tabular}

\section{Figures}

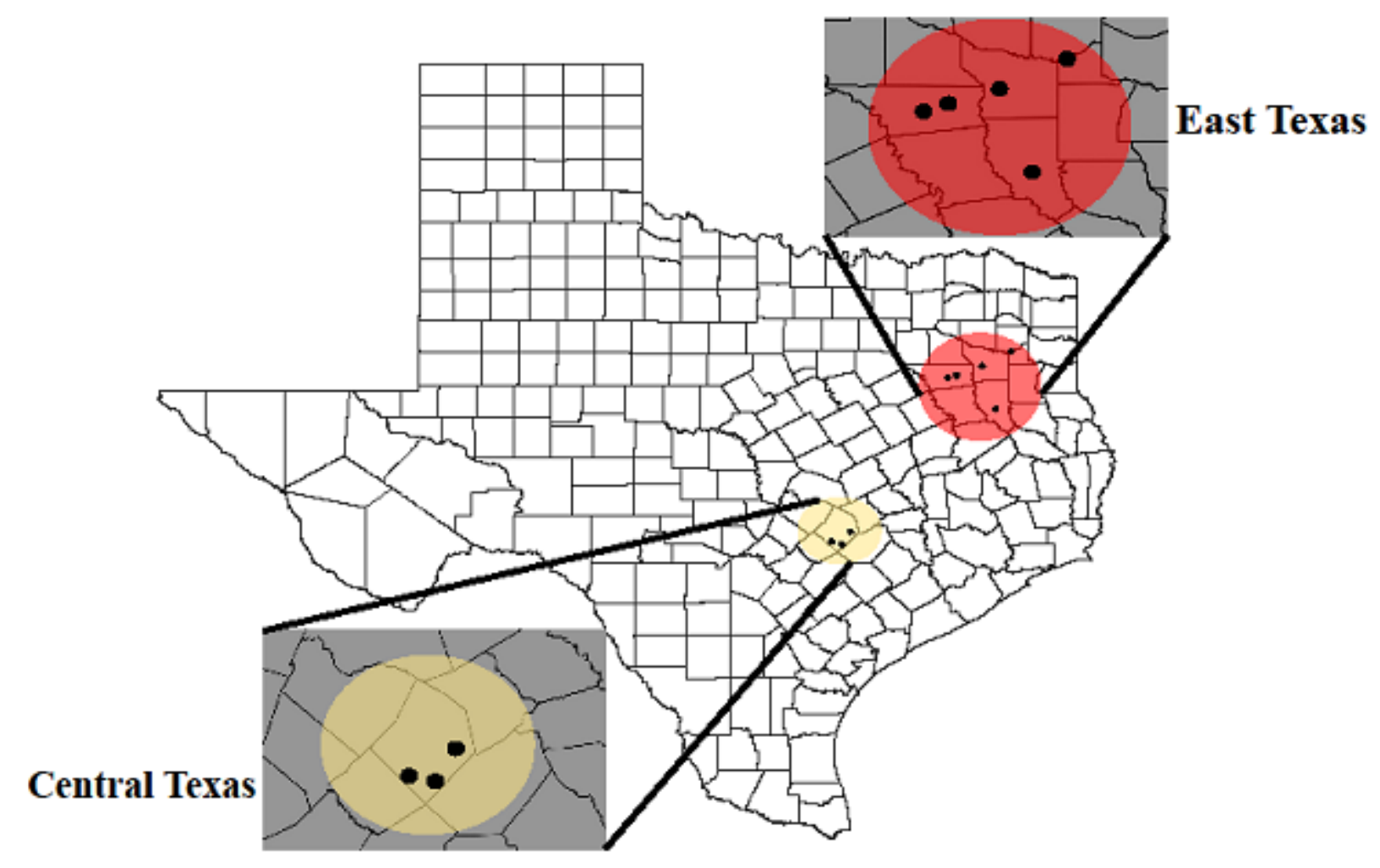

Figure 1 
Map of Texas displaying the East Texas (red) and Central Texas (yellow) sample collection sites
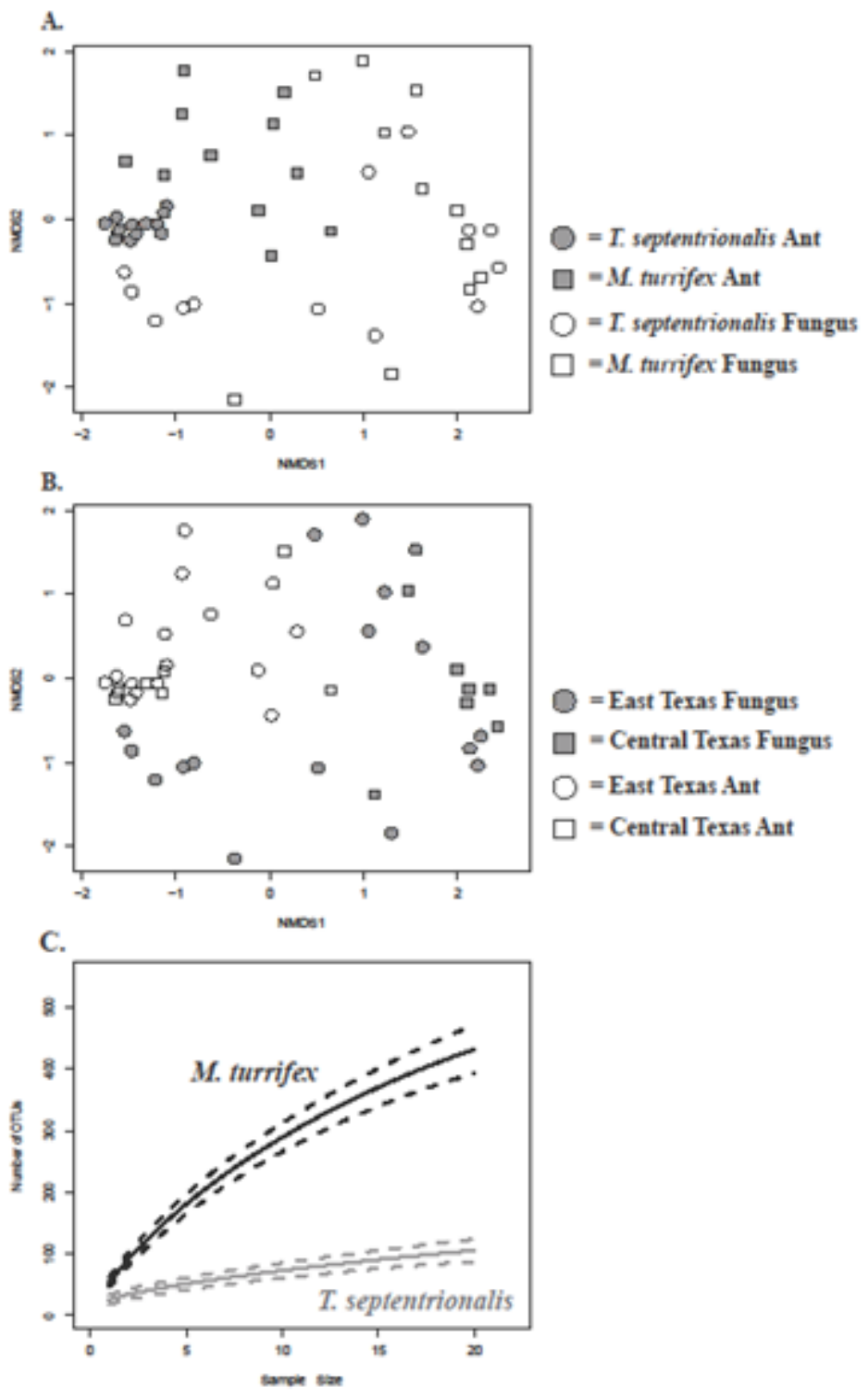

\section{Figure 2}

Non-metric dimensional scaling (NMDS) plots depicting (A.) both ant and fungal samples, with symbols reflecting the samples' associated ant species, and (B.) both ant and fungal samples, with symbols reflecting the samples' associated region. Rarefaction curves (C.) were performed to illuminate any differences in predicted OTU richness between M. turrifex (black) and T. septentrionalis ant samples 
A.

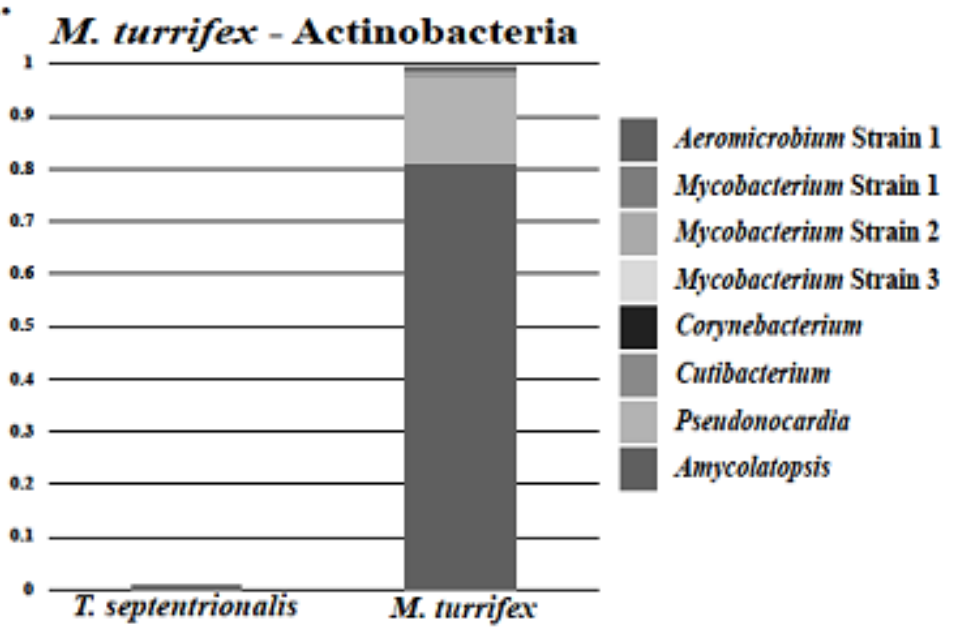

B.

T. septentrionalis - Actinobacteria

\section{1}

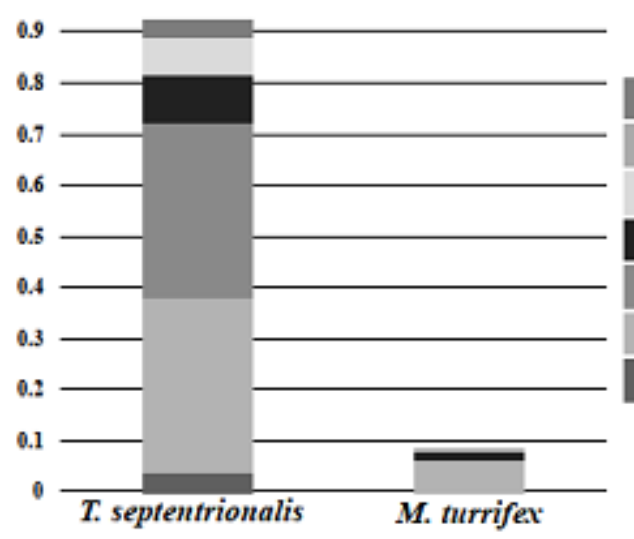

Aeromicrobium Strain 1

Mycobacterium Strain 1

Mycobacterium Strain 2

Mycobacterium Strain 3

Corynebacterium

Cutibacterium

Pseudonocardia

Amycolatopsis

Agrococcus

Unknown Micrococcales

Aeromicrobium Strain 2

Microlunatus

Naumannella

Unknown Intrasporangiaceae

Aeromicrobitum Strain 3

\section{Figure 3}

Bar plots depicting the proportion of the significant OTU abundances within the Actinobacteria community (identified using an indicator species analysis) of ant samples that are driving the Actinobacteria community differences between the two ant species, with separate plots made for the significant taxa corresponding to (A.) M. turrifex and (B.) T. septentrionalis ants. 


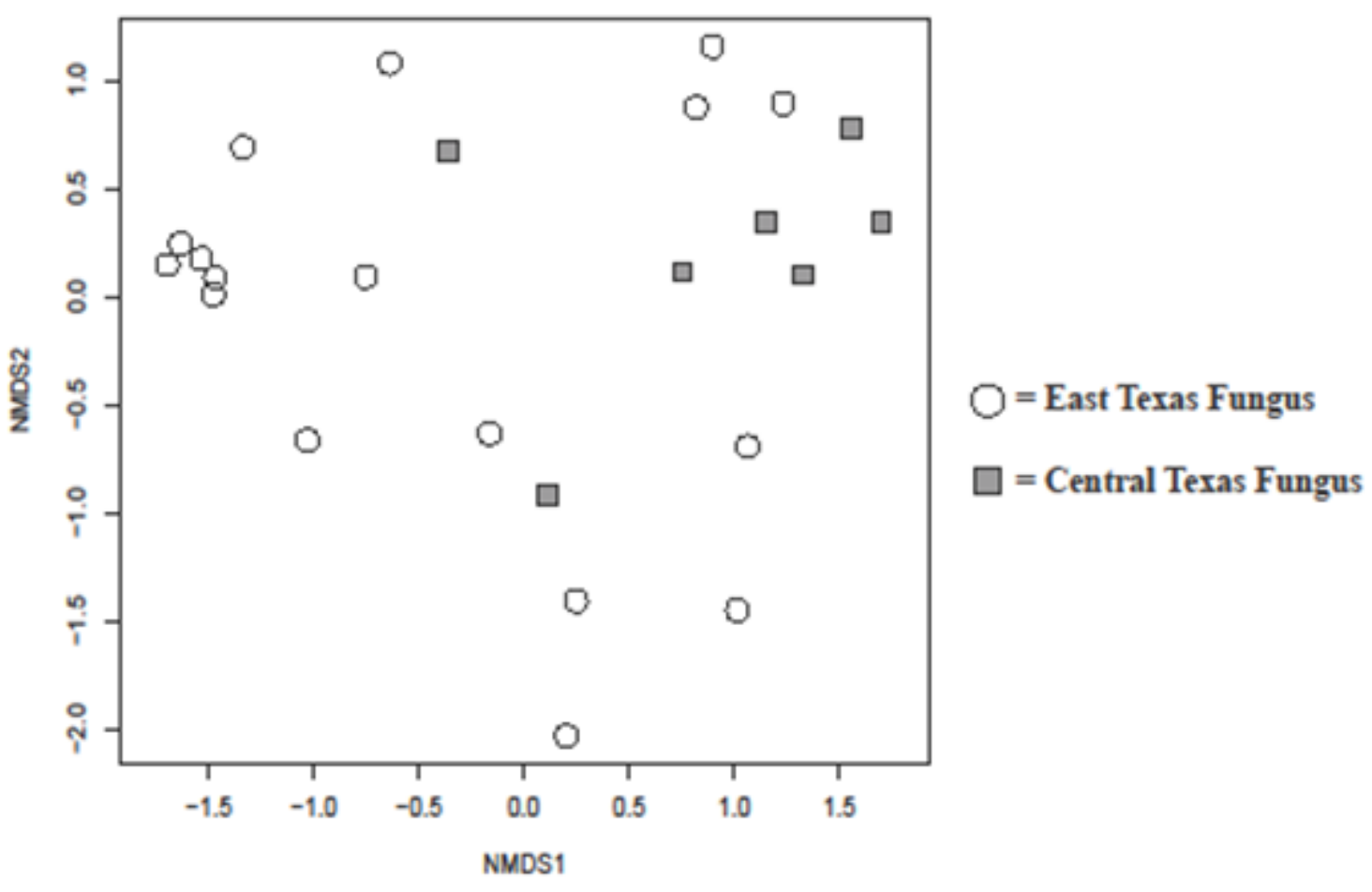

\section{Figure 4}

Non-metric dimensional scaling (NMDS) plot depicting the regionality of fungal samples, with OTUs assigned as Mesoplasma excluded. 
A.

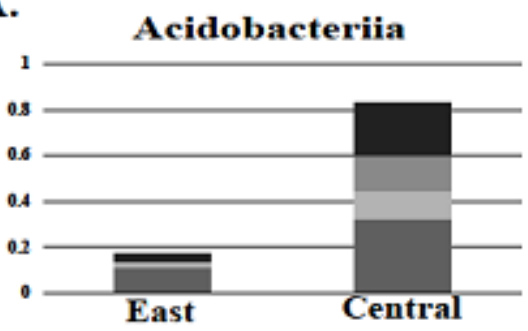

Granulicella

Edaphobacter

Acidobacteriia Subgroup 2 Strain 1

Acidobacteriia Subgroup 2 Strain 2

B.

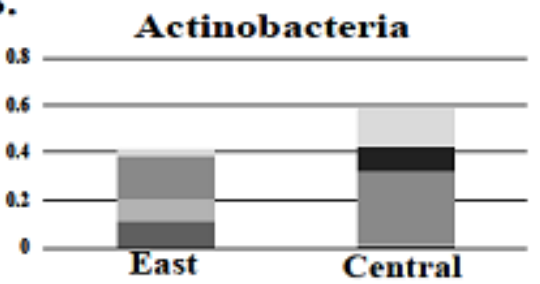

Nocardioides baekrokdamisoli

Mycobacterium Strain 1

Corynebacterium

Unknown Intrasporangiaceae

Naumannella

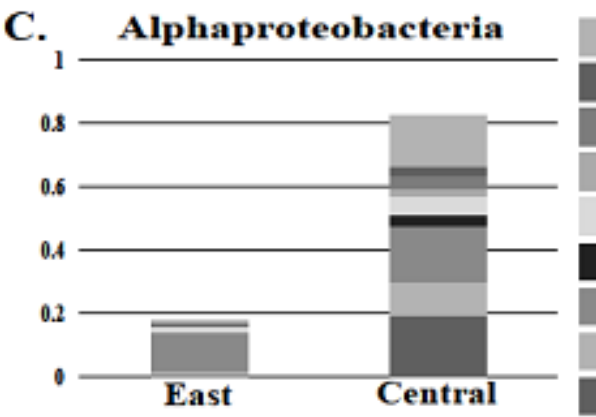

Unknown Caulobacteracea Strain 1

Unknown Beijerinckiaceae Strain 1

Unknown Rhodospirillales

Inquilimus

Unknown Elsterales Strain 1

Unknown Micropepsaceae

Unknown Xanthobacteraceae

Unknown Acetobacteracea Strain 1

Unknown Acetobacteracea Strain 2

\section{Gammaproteobacteria}

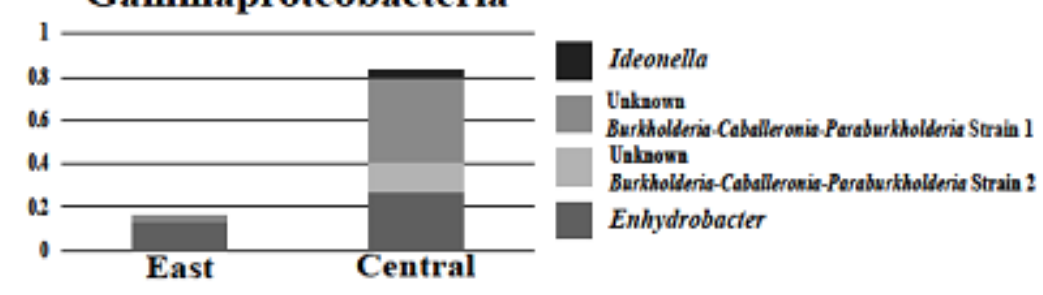

\section{Figure 5}

Bar plots depicting the proportion of the significant OTU abundances within the (A.) Acidobacteriia, (B.) Actinobacteria, (C.) Alphaproteobacteria, and (D.) Gammaproteobacteria communities (identified using an indicator species analysis) of fungal samples that are driving the community differences between the two collection regions, east (East) and central (Central) Texas. 


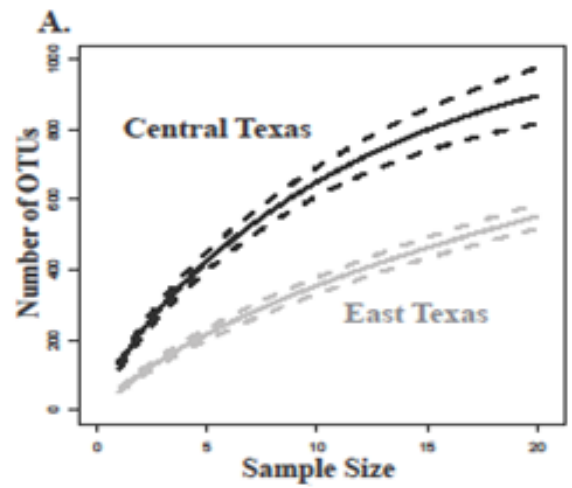

D.
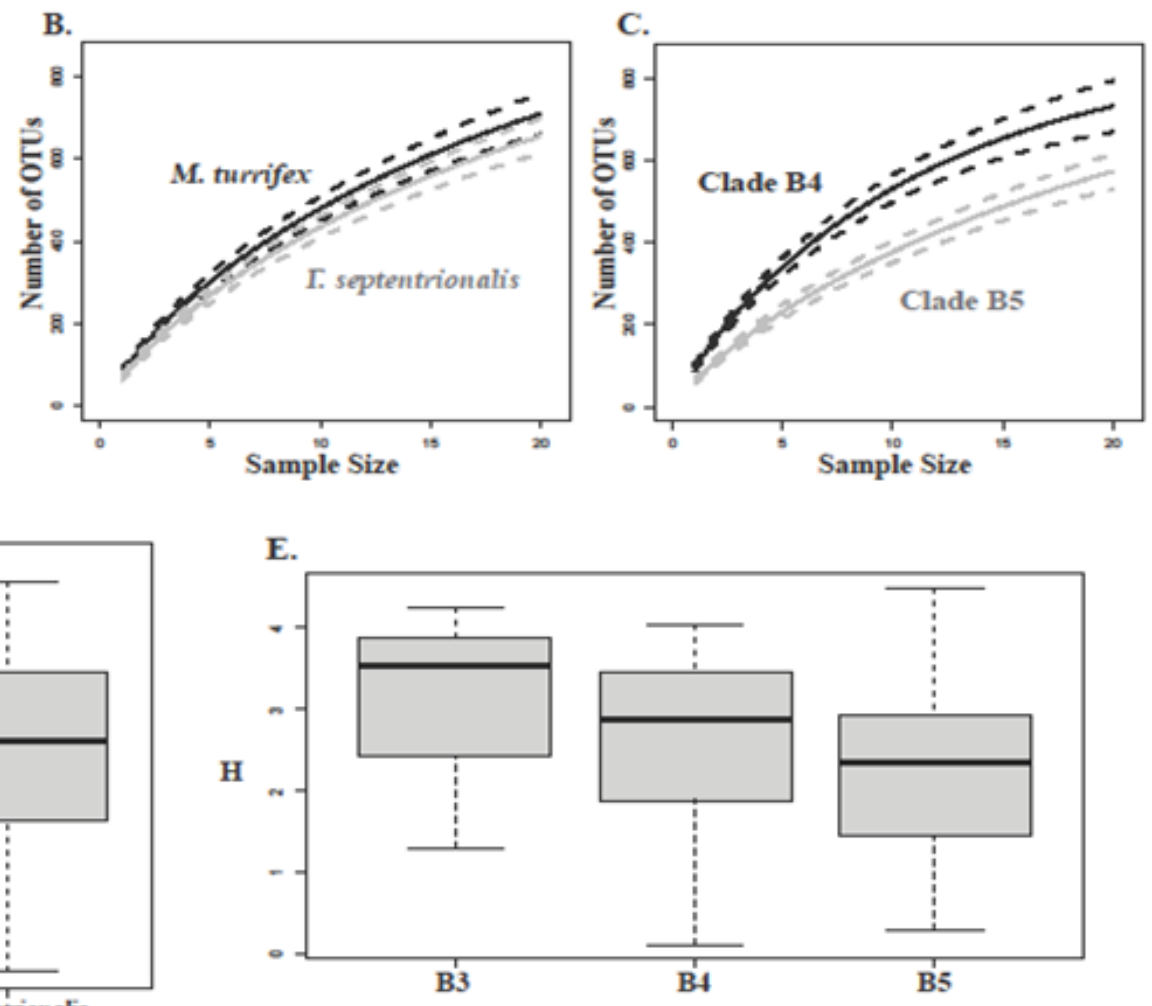

Figure 6

Rarefaction curves between bacterial OTU richness in (A.) Central Texas (black) and East Texas (gray) fungus garden samples, (B.) fungal garden samples associated with M. turrifex (black) and $T$. septentrionalis (gray) ant hosts, and (C.) fungus garden samples genotyped as Clade B4 (black) and Clade B5 (gray). Box plots were made depicting the average Shannon's Diversity Index (H) for (D.) fungal gardens grown by either $M$. turrifex (mean $\mathrm{H}=2.459$ ) or $T$. septentrionalis (mean $\mathrm{H}=2.430$ ) and $(\mathrm{E}$.) Clade B3 (mean H = 3.033), Clade B4 (mean H = 2.581), and Clade B5 (mean H = 2.205). All figures were made without Mesoplasma assigned OTUs included.

\section{Supplementary Files}

This is a list of supplementary files associated with this preprint. Click to download.

- SupplementaryDocumentsTrachymicrobeFinal.docx 